\title{
SUSPENSIÓN Y SUSTITUCIÓN DE LAS PENAS PRIVATIVAS DE LIBERTAD PARA CONDENADOS POR VIOLENCIA DE GÉNERO. LA SITUACIÓN EN ESPAÑA TRAS LA REFORMA DE $2010^{1}$
}

Patricia Faraldo Cabana*

Sumario: 1. Introducción. 2. El régimen especial de suspensión de la ejecución de las penas privativas de libertad. 3. El régimen especial de sustitución de la pena de prisión. 4. Conclusiones.

\section{Introducción}

El objeto de este trabajo es estudiar las peculiaridades de las alternativas a la privación de la libertad para condenados por violencia de género, después de los cambios introducidos por las Leyes Orgánicas (en adelante, LO) 15/2003, de 25 de noviembre, por la que se modifica la LO 10/1995, de 23 de noviembre, del Código Penal, $1 / 2004$, de 28 de diciembre, sobre medidas de protección integral contra la violencia de género, y 5/2010, de 22 de junio, por la que se modifica la LO 10/1995, de 23 de noviembre, del Código Penal. Este estudio se realiza teniendo en cuenta que la LO 1/2004 ha introducido en el derecho penal y penitenciario español la perspectiva de género. ${ }^{2}$

Desde una perspectiva feminista, la contraposición conceptual de "sexo" y "género" expresa que, en tanto el sexo está determinado biológicamente, el género se dota de contenido socialmente. De acuerdo con este entendimiento, la

\footnotetext{
1 Este trabajo ha sido posible gracias a la concesión del Proyecto de Investigación "Medidas alternativas a la privación de libertad" (código 10PXIB101082PR) financiado por la Consellería de Economía e Industria de la Xunta de Galicia, otorgado al equipo investigador que dirijo.

* Catedrática de Derecho Penal, Universidad de la Coruña, España.

2 Sobre ello vid. Faraldo Cabana, P., "Razones para la introducción de la perspectiva de género en Derecho penal a través de la Ley Orgánica 1/2004, de 28 de diciembre, sobre medidas de protección integral frente a la violencia de género", Revista Penal, núm.17, enero 2006, pp. 72-94. En lo que respecta al fundamento que informa la reforma, vid. ampliamente Acalé Sánchez, M., La discriminación hacia la mujer por razón de género en el Código Penal, Reus, Madrid, 2006, pp. 109 ss.

${ }^{3}$ Así lo reconoce la Real Academia Española en su informe de 19 de mayo de 2004 sobre la expresión "violencia de género" (disponible en la página web http://es.search.yahoo.com/search?p=informe+de+la+Real+Academia + sobre+violencia $+\mathrm{de}+\mathrm{g} \% \mathrm{C} 3$ $\%$ A9nero\&fr=yfp-t-501\&ei $=\mathrm{UTF}-8 \&$ meta $=\mathrm{vl} \% 3 \mathrm{D})$, al apuntar que "con el auge de los estudios feministas, en los años setenta del siglo XX se comenzó a utilizar en el mundo anglosajón el término gender con el sentido de 'sexo de un ser humano' desde el punto de vista específico de las diferencias sociales y culturales, en oposición a las biológicas, existentes entre hombres y mujeres. Tal sentido específico ha pasado del inglés a otras lenguas, entre ellas el español. Así pues, mientras que con la voz sexo se designa una categoría meramente orgánica, biológica, con el término género se ha venido aludiendo a una categoría sociocultural que implica diferencias o desigualdades de índole social, económica, política, laboral, etc.” (cursivas en el original).
} 
Faraldo - Suspensión y sustitución de las penas privativas de libertad...

perspectiva de género no es más que "un instrumento para descubrir y comprender los mecanismos que en la práctica - a pesar del reconocimiento formal del derecho de igualdad- permiten y mantienen la subsistencia de la primacía cultural de los valores androcéntricos tanto en la sociedad como en el Derecho... que permitirá avanzar en la consecución de la igualdad material, sustantiva y real". ${ }^{4}$

Se trata de un tema que se enmarca, pues, dentro de la mal llamada violencia doméstica ${ }^{5}$ o violencia contra la mujer ${ }^{6}$, en suma, la violencia de género ${ }^{7}$, concepto que en España ha quedado notablemente indeterminado.

${ }^{4}$ Montalbán Huertas, I., Perspectiva de Género: criterio de interpretación internacional y constitucional, CGPJ, Madrid, 2004, p. 222. Vid. también Carreras, M., Aproximación a la jurisprudencia feminista, Ayuntamiento de Alcalá de Henares, Alcalá de Henares, 1994, pássim; Fernández, R., "El derecho penal como instrumento imprescindible para la prevención de la violencia contra las mujeres", en Calvo García, M. (Coord.), La respuesta desde las instituciones y el Derecho frente al problema de la violencia doméstica en Aragón, Dykinson, Madrid, 2005, pp. 194 ss.

${ }^{5}$ Expresión que resulta demasiado amplia, porque abarca la violencia ejercida en el hogar contra cualquier miembro de la familia. Y por otro lado, en un entendimiento literal, es demasiado restrictiva, porque excluye la violencia ejercida contra la ex pareja o la pareja actual con la que no se convive.

${ }^{6}$ Expresión que resulta demasiado restrictiva, pues no alude a la raíz última de esa violencia, la estructura social patriarcal, ni tampoco aclara que se trata no de violencia contra cualquier mujer, sino de violencia contra la mujer que fuere o hubiere sido esposa, o estuviere o hubiere estado ligada al autor por análoga relación de afectividad, aun sin convivencia.

7 La expresión "violencia de género" es un barbarismo, pero permite poner el acento en el carácter estructural de la violencia contra la mujer en la pareja, fruto de categorías, roles y diferencias culturales y sociales entre hombre y mujer que se han transmitido y mantenido durante siglos, e instrumento para conseguir la subordinación de la mujer a los intereses del hombre. Vid. entre otros COMAS D'Argermir I Cendra, M./ Queralt Jiménez, J. J., "La violencia de género: política criminal y ley penal", en Jorge Barreiro, A., y otros, Homenaje al Profesor Dr. Gonzalo Rodríguez Mourullo, ThomsonCivitas, Navarra, 2005, pp. 1.185 ss.; Gómez Pardos, L./ López Valencia, E. M., "El fenómeno de la violencia doméstica y su tratamiento legislativo e institucional. Especial referencia a la Comunidad Autónoma aragonesa", en Calvo García, M. (Coord.), La respuesta desde las instituciones y el Derecho frente al problema de la violencia doméstica en Aragón, Dykinson, Madrid, 2005, pp. 21 ss.; Laurenzo Copello, P., "La violencia de género en la Ley Integral: valoración político-criminal", Jueces para la Democracia, núm. 54, noviembre 2005, pp. 20-23; Maqueda Abreu, M. L., "La violencia de género. Entre el concepto jurídico y la realidad social”, Revista Electrónica de Ciencia Penal y Criminología 08-02 (2006), pp. 1 ss. Sobre la relación entre la violencia doméstica y la de género, vid. ampliamente Ramon Ribas, E., "Las relaciones entre los delitos de violencia de género y violencia doméstica", en Puente Aba, L. M. (Dir.), La respuesta penal a la violencia de género. Lecciones de diez años de experiencia de una política criminal punitivista, Comares, Granada, 2010, pp. 19 ss.; del mismo autor, "Los delitos de violencia de género: objeto de protección", en Ramon Ribas, E./ Arrom Loscos, R./ Nadal Gómez, I., La protección frente a la violencia de género: tutela penal y procesal, Dykinson, Madrid, 2010, pp. 13 ss.

${ }^{8}$ En el que se ha propuesto incluir, junto a los delitos previstos en los arts. 153, maltrato no habitual, y 173.2, maltrato habitual, también los delitos de amenazas, art. 171.4, 5 y 6, y coacciones, art. 172.2 CP, fruto de la reforma operada por la LO 1/2004. Así, Sanz Mulas en Sanz Mulas, N./ González Bustos, M. A./ Martínez Gallego, E. M. (Coords.), Ley de Medidas de Protección Integral contra la Violencia de Género (LO 1/2004, de 28 de diciembre), Iustel, Madrid, 2005, p. 159. A ellos hay que añadir el art. $148.4^{\circ}$ CP. Cfr. Sánchez García De Paz, I., “Artículo 83”, en Gómez Tomillo, M. (Dir.), Comentarios al Código Penal, Lex Nova, Valladolid, 2010, p. 392. Ésta es la posición que se adopta en el texto. Por su parte, señala que habría que incluir todos los delitos que impliquen 
La determinación de qué delitos cabe incluir bajo la expresión violencia de género cobra especial importancia desde el momento en que la normativa que vamos a analizar es aplicable, de acuerdo con su tenor literal, a los delitos relacionados con la violencia de género (arts. 83.1, último párrafo, y 88.1, último párrafo, CP).

Conviene resaltar que nos encontramos ante un régimen especial, ya que, a diferencia del régimen común, las alternativas a la prisión para condenados por delitos relacionados con la violencia de género prevén la obligatoria imposición de reglas de conducta basadas en la protección de la víctima, a través de prohibiciones

"violencia física y psicológica, incluidas las agresiones a la libertad sexual, las amenazas, las coacciones o la privación arbitraria de libertad", siempre que los cometa quien sea o haya sido pareja de la víctima, de acuerdo con lo dispuesto en el art. 1.3 LO 1/2004, Laurenzo Copello, P., "El modelo de protección reforzada de la mujer frente a la violencia de género: valoración políticocriminal", en AA.VV., La ley de medidas de protección integral contra la violencia de género, Cuadernos penales José María Lidón, núm. 2, Universidad de Deusto, Bilbao, 2005, pp. 99-100, nota núm. 20; de la misma autora "La violencia de género", cit., p. 23, nota núm. 22. A favor de este entendimiento amplio vid. también Ceres Montes, J. F., "Las reformas penales en la fase de ejecución de sentencias penales: en especial la suspensión, la sustitución y la expulsión del territorio nacional”, en Castellano Rausell, P. (Dir.), Las últimas reformas penales, Cuadernos de Derecho Judicial III-2005, CGPJ, Madrid, p. 323; Puente Segura, L., Suspensión y sustitución de las penas, La Ley, Madrid, 2009, pp. 150-155. La Circular 4/2005, de 18 de julio, de la Fiscalía General del Estado, señala que esta expresión “deberá ser interpretada conjugando el artículo 1 LO 1/2004 en relación con las normas que determinan la competencia en el orden penal de los Juzgados de Violencia sobre la Mujer. De forma que por "delito relacionado con la violencia de género" se entenderá aquellos que, siendo competencia de los Juzgados de Violencia sobre la Mujer conforme al artículo $87 \operatorname{ter} 1$ a) y b) de la LOPJ..., hayan tenido como sujeto pasivo a la mujer que fuere o hubiere sido esposa, o que estuviere o hubiere estado ligada al autor por una análoga relación de afectividad, aun sin convivencia" (apartado IV.G). Similar Mata y Martín, R. M., "Modificaciones jurídico-penales de la LO 1/2004, de medidas de protección integral contra la violencia de género", Revista de Derecho y Proceso Penal, núm. 15, 2006-1, pp. 41-42. Para Roig Torres, M., "La suspensión y la sustitución de las penas privativas de libertad de los delitos relacionados con la violencia de género", Revista de Derecho y Proceso Penal, núm. 15, 2006-1, pp. 118-123, basta que se trate de un delito que comporte uso de violencia física o psíquica, pudiendo ser uno de los delitos enumerados al definir las competencias de los juzgados de violencia contra la mujer o cualquier otro violento, siempre que concurra el especial vínculo entre las partes (p. 123). Sobre cómo se ha de entender la declaración contenida en el art. 1 LO 1/2004, vid. Acalé Sánchez, M., "El artículo primero de la Ley Orgánica 1/2004, de 28 de diciembre, de protección integral contra la violencia de género: el concepto de violencia de género", en Faraldo Cabana, P. (Dir.), Política criminal y reformas penales, Tirant lo Blanch, Valencia, 2007, pp. 35-76; de la misma autora, La discriminación, cit., pp. 63 ss.

${ }_{9}^{9}$ Muy críticos sobre la utilización de esta fórmula, visto que se carece de un concepto legal de violencia de género que sea aplicable al ámbito penal, Íñigo Corroza, E., “Aspectos penales de la LOVG, de 28 de diciembre", en Muerza Esparza, J. (Coord.), Comentario a la Ley Orgánica de Protección Integral contra la Violencia de Género. Aspectos jurídico penales, procesales y laborales, Aranzadi, Pamplona, 2005, p. 30; Manjón-Cabeza Olmeda, A., "Violencia de género: discriminación positiva, perspectiva de género y Derecho penal. Algunas cuestiones sobre la competencia de los nuevos Juzgados de Violencia sobre la Mujer", en Aragoneses Martínez, S., y otros, Tutela penal y tutela judicial frente a la violencia de género, Colex, Madrid, 2006, pp. 21-24. 
Faraldo - Suspensión y sustitución de las penas privativas de libertad...

de aproximación y comunicación, y en el tratamiento del maltratador, además de recoger un catálogo de penas sustitutivas distinto del previsto con carácter general. En este trabajo se prestará particular atención a la aplicación obligatoria del tratamiento del agresor como regla de conducta y a la previsión de los trabajos en beneficio de la comunidad y la localización permanente como penas sustitutivas analizando, en particular, si estas medidas pueden contribuir a una protección más eficaz de la víctima. En otros lugares me he pronunciado ya en torno a la imposición obligatoria de las prohibiciones de aproximación y comunicación como reglas de conducta en la suspensión y sustitución en el caso de condenas por delitos relacionados con la violencia de género. ${ }^{10} \mathrm{Al}$ efecto baste recordar aquí que la pérdida de control sobre el proceso penal y sus consecuencias por parte de la mujer que ha denunciado el delito, que se inicia con la detención o prisión provisional del agresor como medida cautelar aunque ella no la solicite y con el hecho de que la acusación será sostenida por el ministerio fiscal aunque ella se retire, llega a sus últimas consecuencias en la imposición por ley del alejamiento del maltratador no sólo como medida cautelar durante el proceso, sino también como pena accesoria en la condena y, lo que es más discutible, como regla de conducta cuando se aplica una medida alternativa a la prisión, sea ésta la suspensión de la ejecución de la pena de prisión o la sustitución de la privación de libertad por otra pena de distinta naturaleza.

Con el fin de luchar contra la falta de intervención del derecho penal en un problema cuya solución se buscaba tradicionalmente en el seno de la familia, siendo considerado como un asunto privado ${ }^{11}$, y en vista del estudiado ciclo de la violencia contra la mujer en la pareja y del síndrome de la mujer maltratada ${ }^{12}$, se

\footnotetext{
${ }^{10}$ Vid. Faraldo Cabana, P., "Tendencias de política criminal en el control penal de la violencia de género: alternativas a la privación de libertad y vicisitudes de la ejecución de la pena de prisión para condenados por violencia de género", en Faraldo Cabana, P. (Dir.), Política criminal y reformas penales, Tirant lo Blanch, Valencia, 2007, pp. 139-204; "Seguridad de las víctimas de violencia de género. Análisis de las alternativas a la ejecución de las penas privativas de libertad para condenados por delitos relacionados con la violencia de género", en Dores, A. P. (coord.), Ciências da Emêrgencia. Exercícios interdisciplinares em Ciências Sociais e Humanas, Editora Digital LibrosEnRed, Portugal, 2008, pp. 301-324; "Las penas principales de los delitos relacionados con la violencia de género", en AA.VV., Constitución, derechos fundamentales y sistema penal (Semblanzas y estudios con motivo del setenta aniversario del profesor Tomás Salvador Vives Antón). Tomo I, Tirant lo Blanch, Valencia, 2009, pp. 569590; Las probibiciones de aproximación, comunicación y residencia en el derecho penal español, Tirant lo Blanch, Valencia, 2009; y "Las penas de los delitos relacionados con la violencia de género. Especial referencia a la prohibición de aproximación y su quebrantamiento", en Puente Aba, L. M. (Dir.), La respuesta penal a la violencia de género. Lecciones de diez años de experiencia de una política criminal punitivista, Comares, Granada, 2010, pp. 153-212.

${ }^{11}$ Sobre la importancia de la distinción entre público y privado en el tratamiento de la violencia de género vid. Schneider, E. M., “The Violence of Privacy”, Connecticut Law Review, Vol. 23, 1991, pp. 985-996.

${ }^{12} \mathrm{La}$ teoría del ciclo de la violencia fue formulada por Walker, L. E., "Treatment Alternatives for Battered Women", en Roberts Chapman, J./ Gates, M. (Ed.), The victimization of women, Beverly Hills/ London, Sage, 1978, pp. 146 ss.; de la misma autora, The Battered Woman Syndrom, Springer, New York, 1984. Se basa en el concepto de refuerzo conductual. Supone la existencia de tres fases:
} 
solicitó en su día que la detención del agresor por la policía al intervenir en un incidente de violencia doméstica se convirtiera en la regla y no en la excepción, y que la retirada de la denuncia por parte de la víctima no supusiera el fin de las actuaciones procesales. ${ }^{13}$ Fue el punto de arranque de las llamadas "no drop policies" "14, basadas en marginar la voluntad de la víctima en la decisión sobre el inicio, la continuación o la finalización del procedimiento penal, así como sobre las medidas cautelares y penas a imponer, con el fin de transmitir la idea de que se trata de un problema público que ha de resolver el derecho penal, y no de una

un período de construcción de la tensión en la pareja, en que la mujer mantiene un cierto control, pues puede evitar o retrasar el maltrato aceptando las exigencias del agresor, la fase de violencia física, en que la mujer pierde el control de la situación, y la fase de arrepentimiento, en la que el maltratador muestra su arrepentimiento por lo ocurrido y se compromete a remediar la situación. La violencia se asocia a un refuerzo inmediato, la expresión de arrepentimiento, y a un potencial refuerzo demorado en el tiempo, la posibilidad de un cambio de conducta. La creencia de la mujer de que debe potenciar con su conducta los aspectos positivos del comportamiento de su pareja hace que se responsabilice a sí misma por los nuevos episodios de violencia, surgiendo sentimientos de culpabilidad y de baja autoestima cuando sus expectativas no se ven cumplidas. Sobre la relación de esta explicación psicológica del maltrato con enfoques psicologicistas del sistema penal que refuerzan los estereotipos negativos sobre la mujer maltratada, impidiendo que se efectúe la necesaria conexión con el contexto social y legal y reduciendo la cuestión a los aspectos individuales, de forma que acaban excusando el comportamiento violento al percibir a la víctima como un sujeto irracional, vid. Hanna, C., "No right to choose: mandated victim participation in domestic violence prosecutions", Harvard Law Review, Vol. 109, June 1996, núm. 8, pp. 1878 ss. En efecto, resulta interesante constatar que Walker, tras describir el ciclo de la violencia, afirma que a corto plazo la única salida para la mujer es el fin de su relación con el agresor. Cfr. Walker, L. E., "Treatment Alternatives", cit., p. 155.

13 Destaca la inexistencia de una discusión en España acerca de cuál es el sistema más ventajoso para la mujer maltratada, si la configuración como delito público o semipúblico, Larrauri Pijoán, E., “¿Por qué retiran las mujeres maltratadas las denuncias?”, Revista de Derecho Penal y Criminología, núm. 12, $2^{\text {a }}$ época, julio 2003, pp. 293 ss., quien alude a la tendencia a transformar el maltrato en un delito público, eliminando o restringiendo la posibilidad de disponer del proceso por parte de la víctima.

${ }^{14}$ Sobre ellas vid. Corsilles, A., "No drop policies in the prosecution of domestic violence cases: Guarantee to action or dangerous solution?", Fordham Law Review, Vol. 63, 1994, pp. 853-863; Edwards, S., "Violence against women: feminism and the law", en Gelsthorpe, L./ Morris, A. (Ed.), Feminist perspectives in criminology, Open University Press, Philadelphia, 1990, p. 158; Friedman, L. N./ Shulman, M., "Domestic Violence. The Criminal Justice Response", en Lurigio, A. J., y otros (Eds.), Victims of Crime. Problems, Policies, and Programs, Sage, Newbury Park, 1990, pp. 94 ss.; Hanna, C., "No right to choose", cit., pp. 1849 ss. En España, Larrauri Pijoán, E., "¿Por qué retiran las mujeres maltratadas las denuncias?", cit., pp. 293 ss. La doctrina justifica estas políticas con base en dos argumentos fundamentales: todos los agentes del control social formal e informal que intervenían en la violencia veían frustrados sus intentos de ponerle fin debido a la actitud contradictoria y reticente de la víctima; ello provocaba que la reacción frente al agresor por parte de la policía y de los tribunales no fuera eficiente, dejando a la mujer desprotegida ante el peligro de ulteriores malos tratos. Vid. por ej., Eadie, T./ Knight, C., "Domestic Violence Programmes: Reflections on the Shift from Independent to Statutory Provision", The Howard Journal, Vol. 41, núm. 2, May 2002, pp. 167-168; Mullender, A., Rethinking Domestic Violence. The Social Work and Probation Response, Routledge, London, 1996, pp. 212-213. 
Faraldo - Suspensión y sustitución de las penas privativas de libertad...

mera cuestión privada ${ }^{15}$, además de pretender eludir de esta forma tanto la presión sobre la víctima por parte del agresor ${ }^{16}$, como el surgimiento de sentimientos de culpabilidad en la mujer. ${ }^{17}$ De ahí se ha pasado a obligar por ley a la separación de la pareja en caso de violencia de género a través de la imposición de medidas dirigidas, en principio, a la tutela de la víctima, pero que se deben aplicar incluso contra su expresa voluntad.

Lo cierto es que se ha interpretado mal la posición feminista que exigía la intervención penal en este ámbito, pues no necesariamente equivale a apoyar que se fuerce a la mujer a una solución sólo penal cuando no desea el fin de la relación con el maltratador. ${ }^{18}$ Hasta ahora se ha fracasado a la hora de entender y atender la propia ambivalencia que manifiesta la mujer a la hora de recurrir a la Administración de Justicia ${ }^{19}$, y la LO 1/2004 no es más que la crónica de un nuevo fracaso al respecto que la LO 5/2010 no ha sabido o no ha querido corregir.

No cabe duda de la efectividad de estas políticas a la hora de transmitir a la comunidad y a las personas implicadas en la violencia la importancia de la cuestión y el carácter delictivo del comportamiento violento. ${ }^{20}$ Más discutido resulta que, en efecto, sirvan a una mejor y mayor protección de la mujer, pues los estudios empíricos muestran limitaciones que impiden llegar a conclusiones firmes en un sentido o en otro. ${ }^{21} \mathrm{Y}$ donde sin duda son contraproducentes es en el caso de que

15 Vid. por todos Duff, R. A., Punishment, Communication and Community, Oxford University Press, New York, 2000, p. 62.

${ }^{16}$ Sobre este efecto en el caso de detención obligatoria del agresor por la policía, vid. Friedman, L. N./ Schulman, M., "Domestic Violence”, cit., p. 98. También Zoellner, L./ Feeny, N./ Álvarez, J./ Watlington, C./ O’Neill, M./ Zager, R./ Foa, E., "Factors associated with the completion of the restraining order process in female victims of partner violence", Journal of Interpersonal Violence, Vol. 15, núm. 10, 2000, pp. 1081 ss.

${ }^{17}$ Cfr. Choudhry, S./ Herring, J., "Righting domestic violence", International Journal of Law, Policy and the Family, Vol. 20, núm. 1, 2006, p. 104.

${ }^{18}$ Cfr. Hanna, C., "No right to choose", cit., p. 1870.

${ }^{19}$ Lo apunta Larrauri Pijoán, E., “¿Por qué retiran las mujeres maltratadas las denuncias”, cit., pp. 271 ss. Señala que en buena medida ello se debe al papel oscilante de la teoría feminista a la hora de explorar las dicotomías público/ privado, particular/ general, víctima/ agente, Hanna, C., "No right to choose", cit., pp. 1885 ss.

${ }^{20}$ Vid. por todos Wills, D., "Domestic violence: The case for aggressive prosecution", UCLA Women's Law Journal, Vol. 7, $\mathrm{N}^{\circ} .2,1997$, pp. 173 ss.

21 Así, vid. el estudio que realizan Hirschel, D./ Hutchison, I. W., "The Voices of Domestic Violence Victims. Predictors of Victim Preference for Arrest and the Relationship Between Preference for Arrest and Revictimization", Crime \& Delinquency, Vol. 49, núm.2, April 2003, pp. 316 ss., acerca de si la obligada detención del agresor produce una disminución real del número o de la gravedad de los actos de violencia y sobre si la preferencia de la víctima por la detención es un factor significativo a la hora de predecir ulteriores actos de violencia. Las respuestas son no y sí, respectivamente, llegando los autores a la conclusión de que la policía debería al menos valorar las preferencias de la víctima cuando acude por un incidente de violencia de género. También de interés Sherman, L. W./ Berk, B. A., "The specific deterrent effects of arrest for domestic assault", American Sociological Review, Vol. 49, 1984, pp. 261 ss.; más reciente, Williams, K. R., “Arrest and 
la mujer decida no colaborar con la acusación o quiera reanudar la convivencia o la relación sentimental con el maltratador, pues se prevén medidas coactivas de diversa índole que pueden dar lugar a una nueva victimización de la mujer a través del sistema penal.

Por otro lado, también resulta excepcional la imposición obligatoria de un tratamiento terapéutico para el penado siempre que se opte por la suspensión de la ejecución de la pena privativa de libertad o por su sustitución. ${ }^{22}$ A diferencia de lo que ocurre en el caso de los delincuentes alcohólicos o drogodependientes ${ }^{23}$, no existe acuerdo doctrinal acerca de la procedencia o no de implementar tratamientos para maltratadores, y menos aun, hay consenso sobre qué programas son los más efectivos. A ello que se añade que en España apenas se han ofrecido diseños razonablemente fundamentados de estos tratamientos, y nuestras carencias en estudios empíricos que analicen la efectividad de los programas existentes son de todos conocidas.

intimate partner violence: Toward a more complete application of deterrence theory", Aggression and Violent Behavior, 10, 2005, pp. 660 ss.

A veces se señala que la efectividad de la prohibición depende en buena medida de la adopción de toda una serie de medidas que permitan una actuación coordinada y eficaz de las fuerzas y cuerpos de seguridad y de los órganos judiciales, desde la asignación de teléfonos móviles a la víctima a la utilización de mecanismos electrónicos de control del agresor; pero la cuestión no es tan fácil. Sobre la vigilancia electrónica, poniendo de relieve que durante la ejecución del programa prácticamente no se producen incidencias, pero que una vez finalizado se recuperan los índices de reiteración delictiva, vid. Bonta, J./ Walace-Capretta, S./ Rooney, J., "Can Electronic Monitoring make a Difference? An Evaluation of Three Canadian Programs", Crime \& Delinquency, Vol. 46, núm. 1, 2000, p. 73; Renzema, M./ Mayo-Wilson, E., "Can electronic monitoring reduce crime for moderate to high-risk offenders?”, Journal of Experimental Criminology, Vol. 1, núm. 2, 2005, pp. 215 ss. Estos resultados hacen pensar que en la violencia de género la vigilancia electrónica y la coordinación policial únicamente supondrá un desplazamiento temporal de las agresiones.

${ }^{22}$ Sólo se prevé algo parecido, que no igual, en el régimen especial de suspensión de la ejecución de la pena para penados que hubiesen cometido el hecho delictivo a causa de su dependencia de las bebidas alcohólicas, drogas tóxicas, estupefacientes, sustancias psicotrópicas u otras que produzcan efectos análogos, en el que se condiciona la concesión a que "se certifique suficientemente, por centro o servicio público o privado debidamente acreditado u homologado, que el condenado se encuentra deshabituado o sometido a tratamiento para tal fin en el momento de decidir sobre la suspensión", quedando en este último caso condicionada la suspensión tanto a que el reo no delinca durante el período que se señale, como a "que no abandone el tratamiento hasta su finalización", dando lugar el incumplimiento de cualquiera de estas dos condiciones a la revocación de la suspensión (art. $87 \mathrm{CP}$ ). Obsérvese que no se impone el sometimiento a tratamiento de deshabituación como regla de conducta, sino que estar deshabituado o sometido a tratamiento es condición previa para conceder la suspensión, aunque en este último caso el mantenimiento en el tratamiento hasta conseguir la deshabituación se convierte en obligatorio. Ello supone que al menos la iniciativa tiene que haber partido del sujeto, lo que garantiza un cierto grado de voluntariedad.

${ }^{23}$ Vid. por todos Suárez-Mira Rodríguez, C., La imputabilidad del consumidor de drogas, Tirant lo Blanch, Valencia, 2000, p. 188. 
Faraldo - Suspensión y sustitución de las penas privativas de libertad...

Esta situación contrasta con lo que sucede en los países anglosajones, donde desde hace años se discute sobre los programas y se evalúa su efectividad, aun reconociendo las limitaciones inherentes a toda investigación sobre este tema. ${ }^{24}$

Pese a esta situación, como veremos, tanto la concesión de la suspensión de la ejecución de la pena de prisión como la de la sustitución de las penas privativas de libertad debe ir acompañada siempre de la regla de conducta consistente en la obligación de someterse a programas específicos de reeducación y tratamiento psicológico.

\section{El régimen especial de suspensión de la ejecución de las penas privativas de libertad}

La suspensión ha experimentado ciertos cambios que pretenden aumentar su eficacia como mecanismo que permite soslayar los graves inconvenientes que plantean las penas privativas de libertad de corta duración de cumplimiento continuado. Entre ellos, siguiendo tendencias que se apuntan en el derecho comparado ${ }^{25}$, cabe destacar la creación y consolidación de un régimen especial de suspensión para condenados por delitos relacionados con la violencia de género. ${ }^{26}$

Con carácter general, la suspensión de la ejecución queda condicionada a que el reo no delinca en el plazo fijado por el juez o tribunal (art. 83.1 CP). También durante este plazo, y siempre que la pena suspendida fuese la de prisión, el juez o tribunal sentenciador, si lo estima necesario, podrá condicionar la suspensión al cumplimiento de las obligaciones o deberes que haya fijado de entre los siguientes:

"1․ Prohibición de acudir a determinados lugares.

\footnotetext{
${ }^{24}$ Sobre esas limitaciones vid. por todos Gondolf, E. W., "Limitations of experimental evaluation of batterer programs", Trauma, Violence and Abuse 2(1), 2001, pp. 53 ss.; Losel, F., "Evaluating the effectiveness of correctional programs: bridging the gap between research and practice", en Bernfield, G. A./ Farrington, D. P./ Leschied, A. W. (Eds.), Offender Rehabilitation in Practice: Implementing and Evaluating Effective Programs, John Wiley, Chichester, 2001, pássim. Ofrecen una revisión de los resultados, a veces contradictorios, de los estudios doctrinales, Wooldredge, J./ Thistlethwaite, A., "Court Dispositions and Rearrest for Intimate Assault", Crime \& Delinquency, Vol. 51, núm. 1, 2005, pp. 75-102.

${ }^{25}$ Cfr. Ford, D. A., et al, "Future Directions", cit., pp. 260-261, quienes destacan el aumento del recurso a la suspensión en la violencia doméstica como vía para forzar la participación del agresor en programas de tratamiento.

26 Apunta Sanz Mulas en Sanz Mulas, N./ González Bustos, M. A./ Martínez Gallego, E. M. (Coords.), Ley de Medidas, cit., p. 160, que se crea una "asimetría en el sistema de la suspensión, que desdibuja la filosofía inicial de este beneficio como una especie de "segunda oportunidad", y que busca, sobre todo, el alejamiento de la prisión a través de las penas alternativas”. Peor sería el panorama si se hubiera atendido la solicitud de la asociación de mujeres juristas Themis, que pedía imponer penas más cortas pero de cumplimiento efectivo, eliminando la posibilidad de suspensión de la pena, tomando como modelo a seguir la regulación del terrorismo. Themis, Consideraciones desde la Asociación de Mujeres Themis a las reformas recientes y en proyecto, de marzo de 2003, disponible en http://www.mujeresjuristasthemis.org/documentos/Penal/index.htm, p. 7.
} 
$2^{\mathrm{o}}$. Prohibición de aproximarse a la víctima, o a aquellos de sus familiares u otras personas que determine el juez o tribunal, o de comunicarse con ellos.

$3^{\circ}$. Prohibición de ausentarse sin autorización del juez o tribunal del lugar donde resida.

$4^{\circ}$. Comparecer personalmente ante el juzgado o tribunal, o servicio de la Administración que éstos señalen, para informar de sus actividades y justificarlas. $5^{\circ}$. Participar en programas formativos, laborales, culturales, de educación vial, sexual, de defensa del medioambiente, de protección de los animales y otros similares.

$6^{\circ}$. Cumplir los demás deberes que el juez o tribunal estime convenientes para la rehabilitación social del penado, previa conformidad de éste, siempre que no atenten contra su dignidad como persona".

En el caso de comisión de los delitos relacionados con la violencia de género es obligatorio para el juez o tribunal condicionar en todo caso la suspensión al cumplimiento de las obligaciones o deberes previstos en las reglas $1^{\mathrm{a}}, 2^{\mathrm{a}}$ y $5^{\mathrm{a}}$ del art. 83.1 CP, según se dispone en el último párrafo de este apartado.

Esta regulación es fruto de varias modificaciones. En primer lugar, de las introducidas por la LO 15/2003, de 25 de noviembre, por la que se modifica la LO 10/1995, de 23 de noviembre, del Código Penal, que obliga a condicionar la suspensión de la ejecución de la pena por delitos contemplados en los arts. 153 y 173.2 CP al cumplimiento de las obligaciones o deberes previstos en las reglas $1^{\mathrm{a}}$ y $2^{\mathrm{a}}$ del art. 83.1 CP, que son las prohibiciones de acudir a determinados lugares y de aproximarse a la víctima o a aquellos de sus familiares u otras personas que determine el juez o tribunal, o de comunicarse con ellos, y que castiga el incumplimiento de las prohibiciones a las que se condiciona la suspensión de la ejecución de la pena de prisión con la revocación de la suspensión, lo que supone una excepción a la regla general conforme a la cual sólo "si el sujeto delinquiera durante el plazo de suspensión fijado, el juez o tribunal revocará la suspensión de la ejecución de la pena" (art. 84.1 CP), mientras que "si el sujeto infringiera durante el plazo de suspensión las obligaciones o deberes impuestos, el juez o tribunal podrá, previa audiencia de las partes, según los casos:

a) Sustituir la regla de conducta impuesta por otra distinta.

b) Prorrogar el plazo de suspensión, sin que en ningún caso pueda exceder de cinco años.

c) Revocar la suspensión de la ejecución de la pena, si el incumplimiento fuera reiterado" (art. 84.2 CP).

La actual redacción también es fruto de la reforma operada por la LO 1/2004, de 28 de diciembre, de medidas de protección integral contra la violencia de género, que eliminó la referencia a "los delitos contemplados en los artículos 153 y 173.2 de este Código" sustituyéndola por "delitos relacionados con la violencia de género", además de introducir la obligación de imponer la condición prevista en la regla $5^{a}$ del art. 83.1 CP. En la misma reforma se modificó la redacción del tercer apartado en el art. 84 $\mathrm{CP}$, que pasa a establecer que "en el supuesto de que la pena suspendida fuera de 
Faraldo - Suspensión y sustitución de las penas privativas de libertad...

prisión por la comisión de delitos relacionados con la violencia de género, el incumplimiento por parte del reo de las obligaciones o deberes previstos en las reglas $1^{\text {a }}, 2^{\mathrm{a}}$ y $5^{\mathrm{a}}$ del apartado 1 del artículo 83 determinará la revocación de la suspensión de la ejecución de la pena".

Por último, la LO 5/2010 ha modificado la regla $5^{a}$ para incluir programas "de defensa del medioambiente" y "de protección de los animales". ${ }^{27}$

Respecto de la regulación vigente debe apuntarse, por una parte, que se deja fuera de este régimen especial el maltrato en el ámbito familiar que no afecte a la mujer sino a otros sujetos pasivos, antes incluido. Tal es el caso, por ej., del maltrato habitual hacia ascendientes o descendientes, con independencia del sexo. $^{28}$

Cierto que los efectos de esta exclusión son poco relevantes, ya que el juez o tribunal siempre puede imponer las obligaciones que considere oportunas según las circunstancias del caso, "pero este tipo de imprevisiones -propias de las urgencias y falta de reflexión a la hora de legislar- abonan el terreno para quienes injustamente reprochan a la Ley Integral un contenido tendencioso y discriminatorio". ${ }^{29}$ De hecho, el Consejo General del Poder Judicial propone en 2011 una reforma legislativa que corrija la situación, introduciendo el término "o doméstica" a continuación de la alusión a la violencia de género en los arts. 83.1, último párrafo, y 88.1, último párrafo, CP. ${ }^{30}$

Por otro lado, en cuanto al catálogo de las obligaciones o deberes que se pueden o deben imponer al condenado, hay que señalar que las cuatro primeras consisten exclusivamente en medidas de control carentes de cualquier contenido asistencial, lo que no parece coherente con el fundamento de la suspensión de la

\footnotetext{
27 Sobre las razones de esta inclusión, vid. Hava García, E., "Suspensión de la ejecución de las penas privativas de libertad (art. 83)", en Álvarez García, F. J./ González Cussac, J. L. (Dirs.), Comentarios a la Reforma Penal de 2010, Tirant lo Blanch, Valencia, 2010, pp. 123-124.

${ }^{28}$ Lo destaca la Circular 4/2005, de 18 de julio, de la Fiscalía General del Estado: "No quedarán amparados en esta expresión (n. de la a., violencia de género), por no aparecer dichos sujetos incluidos en el artículo primero de la LO 1/2004, los cometidos contra los descendientes, menores o incapaces del círculo afectivo de la mujer, aunque hayan sido conocidos por los referidos Juzgados (n. de la a., de Violencia sobre la Mujer), ya que otro entendimiento supondría extender el ámbito de aplicación de las normas procesales de competencia a supuestos sustantivos condicionantes de la ejecución de la pena”. Vid. también, entre otros, Manjón-Cabeza Olmeda, A., "Violencia de género", cit., pp. 19-20, que afirma que se trata de un retroceso, y que "la reforma en este punto merece el más negativo de los juicios"; Mata y Martín, R. M., "Modificaciones jurídicopenales", cit., pp. 57-58, apuntando las incongruencias y desigualdades que se producen.

${ }^{29}$ Laurenzo Copello, P., "El modelo de protección reforzada de la mujer”, cit., p. 100, nota núm. 20.

${ }^{30} \mathrm{Cfr}$. Informe del grupo de expertos y expertas en violencia de género del Consejo General del Poder Judicial acerca de los problemas técnicos detectados en la aplicación de la Ley Orgánica 1/2004, de medidas de protección integral contra la violencia de género y en la de la normativa procesal, sustantiva u orgánica relacionada, y sugerencias de reforma legislativa que los abordan, de enero de 2011, pp. 12-13.
} 
ejecución de la pena ${ }^{31}$ : se trata de la prohibición de acudir a determinados lugares (de imposición obligatoria), prohibición de aproximarse a la víctima, o a aquellos de sus familiares u otras personas que determine el juez o tribunal, o de comunicarse con ellos (de imposición obligatoria), prohibición de ausentarse sin autorización del juez o tribunal del lugar donde resida (de imposición potestativa) y comparecer personalmente ante el juzgado o tribunal, o servicio de la Administración que éstos señalen, para informar de sus actividades y justificarlas (de imposición potestativa). Más sentido que la imposición de estas prohibiciones tiene la obligación de participar en programas formativos y similares ${ }^{32}$, pues permite incidir en las carencias que pueden haber llevado a la comisión del hecho delictivo y de esta forma evitar la reincidencia. ${ }^{33}$ Ahora bien, aunque en mi opinión se puede entender que están incluidos, sería deseable que se hiciera una alusión expresa a "programas específicos de reeducación y tratamiento psicológico", de forma similar a lo que se prevé en la sustitución.

31 Ponen de relieve que la doctrina se había manifestado en general favorable a la posibilidad de incluir reglas de conducta en la suspensión, pero insistiendo en que debían tener carácter asistencial, Larrauri Pijoán, E., "Suspensión y sustitución de la pena en el nuevo Código Penal”, Estudios Penales y Criminológicos XIX, 1996, p. 211; Navarro Villanueva, C., Suspensión y modificación de la condena penal, Bosch, Barcelona, 2002, p. 69. Señala la necesidad de que en las reglas de conducta tengan preeminencia absoluta las medidas de ayuda sobre las de control Sanz Mulas, N., Alternativas a la pena privativa de libertad, Colex, Madrid, 2000, pp. 298 ss. Vid. también Puente Segura, L., Suspensión, cit., p. 154.

32 Sobre el contenido de estos programas formativos de reeducación de maltratadores, vid. Leganés Gómez, S., "Las penas y el tratamiento de los maltratadores", La Ley Penal, núm. 34, 2007, pp. 57 ss.

33 Así, entre otros, Acale Sánchez, M., La discriminación, cit., pp. 340-341; López Lorenzo, V., "La suspensión y la sustitución de la pena tras la LO 15/2003, de 25 de noviembre, de reforma del Código Penal", La Ley Penal, núm. 9, año I, octubre 2004, p. 38. Apunta que esta posibilidad "responde mucho mejor a lo que algunas mujeres esperan del sistema penal", Larrauri Pijoán, E., “¿Por qué retiran las mujeres maltratadas las denuncias?”, cit., p. 302. A favor de un modelo, no se sabe si alternativo o complementario, de política criminal de la violencia contra la mujer que tome como eje el tratamiento del maltratador, vid. Cuello Contreras, J./ Cardenal Murillo, A., "Bien jurídico y técnica legal de la protección penal de la mujer y otras víctimas de la violencia doméstica", en Carbonell Mateu, J. C., y otros (Coords.), Estudios penales en homenaje al profesor Cobo del Rosal, Dykinson, Madrid, 2005, pp. 267-271. El problema es que en la práctica en muchos lugares no existen programas adecuados, como denuncia Ceres Montes, J. F., "Las reformas penales", cit., p. 296. Ya la Circular 1/1998, de 21 de octubre, de la Fiscalía General del Estado, sobre la intervención del ministerio fiscal en la persecución de los malos tratos en el ámbito doméstico y familiar, destacaba "la importancia de la posible obligación del penado a participar en programas formativos durante el tiempo de suspensión” (apartado VI.C).

En los países anglosajones, los estudios cuantitativos efectuados parecen llevar a la conclusión de que los agresores que reciben una pena que es objeto de suspensión sin imposición de reglas de conducta, o bien son castigados sólo con una multa, tienen tres veces más posibilidades de reincidir que los sometidos a prisión, trabajos o "probation". Cfr. Ventura, L. A./ Davis, G., "Domestic Violence : Court Case Conviction and Recidivism”, Violence Against Women, Vol. 11, núm. 2, 2005, pp. 271 ss. 
Faraldo - Suspensión y sustitución de las penas privativas de libertad...

No comparto la postura del Consejo General del Poder Judicial ${ }^{34}$, para el cual estos programas "posibilitan un mejor tratamiento de las causas que han generado el delito, mientras que, en los supuestos de suspensión, sólo se prevé el seguimiento de programas formativos, de menor incidencia en aquéllas", dando a entender que no cabría aplicar un tratamiento en el caso de la suspensión.

No son medidas dirigidas directamente a la protección de la víctima, como las otras, sino a la corrección del responsable del delito ${ }^{35}$, al facilitar su reinserción ${ }^{36}$, lo cual en principio resulta más acorde con el fundamento de la suspensión. ${ }^{37}$

Ahora bien, la adopción de medidas de naturaleza terapéutica sobre el agresor $-\mathrm{y}$ también las formativas tienen esta naturaleza- siempre ha tenido una fuerte oposición desde la perspectiva feminista.

En efecto, si se aborda la violencia de género como un problema de relaciones de poder se niega que en esencia consista en una patología individual que pueda tratarse y corregirse individualmente ${ }^{38}$, aunque no cabe duda de que determinadas patologías, como el alcoholismo ${ }^{39}$ o ciertas enfermedades mentales ${ }^{40}$,

34 Informe, cit., pp. 10-11, proponiendo la modificación. En este sentido, vid. también Paloma Montaño, L. M., "Problemas técnicos detectados en la aplicación de la LO 1/2004, de medidas de protección integral contra la violencia de género", en Marchal Escalona, A. N. (Dir.), Manual de lucha contra la violencia de género, Aranzadi Thomson-Reuters, Cizur Menor, 2010, pp. 397-398.

${ }^{35}$ Como señala en el apartado IV.g) la Circular 4/2004, de 18 de julio, de la Fiscalía General del Estado, relativa a los criterios de aplicación de la Ley Orgánica de medidas de protección integral contra la violencia de género. Sin embargo, muchos autores justifican su imposición con base en la protección de la víctima. Vid. por todos Mata y Martín, R. M., "Modificaciones jurídico-penales", cit., p. 56.

${ }^{36}$ Cfr. Navarro Villanueva, C., Suspensión, cit., p. 72.

${ }^{37}$ La Fiscalía General del Estado, Informe de la Fiscalía General del Estado sobre el tratamiento jurisdiccional de los malos tratos familiares en el año 1999, Madrid, Instituto de la Mujer, 2000, p. 52, sugería ya en 1999 condicionar la suspensión a la imposición de las reglas de conducta del art. 83.1.4 ${ }^{\circ} \mathrm{CP}$ en su redacción original, que permitía imponer la participación en programas de tratamiento.

38 Sobre esta dicotomía vid. Bodelón González, E., "Género y sistema penal: los derechos de las mujeres en el sistema penal”, en Bergalli, R. (Coord.), Sistema penal y problemas sociales, Tirant lo Blanch, Valencia, 2003, p. 479; Larrauri Pijoán, E., “¿Es posible el tratamiento de los agresores de violencia doméstica?", cit., pp. 364-365. Vid. un resumen de las diversas objeciones del movimiento feminista al tratamiento del agresor en Dobash, E. R./ Dobash, P. R., Women, Violence and Social Change, Routledge, London, 1992, pp. 241-242; Osborne, R., Apuntes sobre violencia de género, Bellaterra, Barcelona, 2009, pp. 128-133, desde una perspectiva favorable al tratamiento.

${ }^{39}$ Sobre el efecto del alcoholismo en la reincidencia en la conducta violenta, vid. Gondolf, E. W., "Evaluating batterer counseling programs: A difficult task showing some effects and implications", Agression and Violent Behavior, Vol. 9, Issue 6, 2004, pp. 620-621; Johnson, H., "The role of alcohol in male partners' assaults on wives", Journal of Drug Issues, Vol. 30, núm. 4, 2000, pp. 725 ss.; Walters, G., "Disposed to aggress? In search of the violence-prone personality", Aggression and Violent Behavior, Vol. 5, Issue 2, 2000, pp. 177 ss.

40 Vid. Cano Valero, J., “Aspectos psiquiátricos de la violencia doméstica contra la mujer”, en López Arminio, M. J. (Coord.), Tratamiento penal de la violencia doméstica contra la mujer, Universidad de 
pueden tener una importante incidencia en el fenómeno y deben ser objeto de tratamiento en el caso concreto. A ello se añade que el tratamiento del agresor supone una desviación de fondos hacia el responsable del maltrato, en vez de destinarlos a la víctima. ${ }^{41}$

Además, se cuestiona su eficacia en dos sentidos: por un lado, en lo que se refiere a conseguir que el agresor abandone la conducta violenta ${ }^{42}$; por otro, en lo que respecta a transmitir a la sociedad el mensaje de que el maltrato no es una cuestión privada, sino de interés público. ${ }^{43}$

Cádiz-Ayuntamiento de Jerez, Jerez, 1999, pp. 135 ss.; Lorente Acosta, M., “Síndrome de agresión a la mujer. Síndrome de maltrato a la mujer”, en López Arminio, M. J. (Coord.), Tratamiento penal de la violencia doméstica contra la mujer, Universidad de Cádiz-Ayuntamiento de Jerez, Jerez, 1999, pp. 133 ss., que antes de analizar al agresor patológico destaca que "en la mayoría de los casos el agresor es una persona "normal" que no se puede encuadrar dentro del grupo de las psicopatías o trastornos de la personalidad ni como enfermo mental". Apunta la existencia de una tendencia a ajustar el tratamiento a las peculiaridades de cada individuo o tipo de maltratador Medina, J. J., Violencia contra la mijer en la pareja: investigación comparada y situación en España, Tirant lo Blanch, Valencia, 2002, p. 518. Vid. un estudio de los programas adecuados para agresores con rasgos psicopáticos en Gondolf, E. W./ White, R., "Batterer program participants who repeatedly reassault: Psychopathic tendencies and other disorders", Journal of Interpersonal Violence, 16, 2001, pp. 361 ss.

${ }^{41}$ Recogen las posiciones encontradas a la hora de buscar y obtener fondos para los programas a favor de las víctimas y de tratamiento del agresor Scourfield, J. B./ Dobash, R. P., "Programmes for Violent Men: Recent Developments in the UK”, The Howard Journal, Vol. 38, núm. 2, May 1999, p. 133. Sobre esta cuestión vid. Mullender, A., La violencia doméstica, Paidós, Barcelona, 2000, pp. 343-346, con ulterior bibliografía. Afirma que esta objeción se basa en una falsa dicotomía, pues si el tratamiento reduce la reincidencia y/o la gravedad de la violencia doméstica redundará también en beneficio de la víctima, Hoyle, C., Negotiating Domestic Violence: Police, Criminal Justice and Victims, Clarendon Press, Oxford, p. 227.

42 Cfr. Lorente Acosta, M., "Síndrome de agresión", cit., p. 141. Vid. entre otros Aldarondo, E., "Evaluating the efficacy of interventions with men who batter", en Aldarondo, E./ Mederos, F. (Eds.), Men who batter: Intervention and prevention strategies in a diverse society, New York, Civic Research Institute, 2002, pp. 31 ss.; Davis, R. C./ Taylor, B. G., "Does batterer treatment reduce violence? A synthesis of the literature", Women and Domestic Violence: An Interdisciplinary Approach, 10, pp. 69 ss.; Gondolf, E. W., "Batterer Programs: What We Know and Need to Know", Journal of Interpersonal Violence, Vol. 12, núm. 1, 1997, pp. 83 ss.; del mismo autor, "Evaluating batterer counseling programs”, cit., pp. 606 ss.; Mullender, A., La violencia doméstica, cit., pp. 339-343. Desde un enfoque pragmático apunta Larrauri Pijoán, E., “¿Es posible el tratamiento de los agresores de violencia doméstica?”, cit., p. 366, que debemos preguntarnos no sólo si los programas funcionan, sino qué otro tipo de pena se ha demostrado más eficaz.

${ }^{43}$ En España fue este el temor sentido tanto por organizaciones feministas como por los políticos cuando se discutía sobre la procedencia o no de implementar tratamientos para los agresores. Vid. las referencias en Larrauri Pijoán, E., “¿Es posible el tratamiento de los agresores de violencia doméstica?”, cit., pp. 359 ss., quien apunta que en la práctica española no hablamos del tratamiento como alternativa a la pena de prisión, sino de elegir entre la suspensión sin tratamiento o la suspensión con tratamiento, de forma que se desmonta el argumento: "imponer la obligación de asistir a un programa de rehabilitación no es una respuesta de menor intensidad a lo que sucede habitualmente, sino de mayor intensidad a la práctica habitual" (p. 364). 
Faraldo - Suspensión y sustitución de las penas privativas de libertad...

En los países anglosajones, en los que la única respuesta del sistema penal puede ser la obligación de someterse a tratamiento, se añade que aunque estas medidas terapéuticas responden en muchas ocasiones a lo que la mujer realmente desea, que es el cese de la violencia, lo cierto es que transmiten una impresión equivocada al reforzar la idea de que el maltrato merece una respuesta de carácter social, no penal. ${ }^{44}$

Ahora bien, el sesgo de la discusión es distinto en España, donde se ha pasado de un rechazo sin paliativos a discutir qué programas son los más adecuados ${ }^{45}$, olvidando que las diferentes perspectivas explicativas del maltrato suponen intervenciones en diferentes niveles y con los distintos sujetos implicados en el fenómeno.

Las perspectivas cultural, estructural y jurídica apuntan a la necesidad de intervenir sobre factores sociales de amplio espectro, no tanto o no primordialmente sobre los sujetos protagonistas del maltrato. Sólo las perspectivas psicopatológica y de la interacción proponen intervenciones con el agresor y/o con la propia víctima. ${ }^{46}$

Igualmente se olvida que bajo la etiqueta de "maltratador" se esconden tipologías muy diversas de sujetos, y que la violencia de género abarca un amplio conjunto de conductas de muy distinta frecuencia, intensidad y gravedad, cuyas causas siguen siendo discutidas. ${ }^{47}$

\footnotetext{
${ }^{44}$ Cfr. Friedman, L. N./ Shulman, M., "Domestic Violence", cit., p. 96.

${ }^{45}$ Lo pone de relieve Larrauri Pijoán, E., “¿Es posible el tratamiento de los agresores de violencia doméstica?", cit., p. 363.

${ }^{46}$ En los últimos años se ha incrementado el interés por la investigación psicológica dirigida a identificar las carencias que llevan a un hombre a agredir a su pareja, probablemente debido a que las otras perspectivas exigen intervenciones costosas y a largo plazo difícilmente evaluables. Vid. una revisión de la literatura anglosajona sobre la perspectiva centrada en aspectos psicológicos en Cunningham, A./ Jaffe, P. G./ Baker, L./ Dick, T./ Malla, S./ Mazaheri, N./ Poisson, S., TheoryDerived Explanations of Male Violence Against Female Partners: Literature Update and Related Implications for Treatment and Evaluation, London Family Court Clinic, London, 1998; Jasinski, J. L./ Williams, L. M., Partner Violence: A Comprehensive Review of 20 Years of Research, Sage, London, 1998.

${ }^{47}$ Sobre el grado en que la elaboración de tipologías de maltratadores puede contribuir a determinar cuál es el tratamiento más adecuado, vid. Faulkner, K. K./ Cogan, R./ Nolder, M./ Shooter, G., "Characteristics of men and women completing cognitive/behavioral spouse abuse treatment", Journal of Family Violence, Vol. 6, núm. 3, 1991, pp. 243-253; Gondolf, E. W., "Batterer programs”, cit., pp. 83 ss.; Hamberger, L. K./ Hastings, J. E., "Characteristics of spouse abusers: Predictors of treatment acceptance", Journal of Interpersonal Violence, núm. 1, 1986, pp. 363-373; de los mismos autores, "Counseling male spouse abusers: Characteristics of treatment completers and dropouts", Violence and Victims, núm. 4, 1989, pp. 131 ss.; Langhinrichsen-Rohling, J./ Huss, M. T./ Ramsey, S., "The Clinical Utility of Batterer Typologies", Journal of Family Violence, Vol. 15, núm. 1, 2000, pp. 37 ss. Vid. un resumen de la discusión en Echeburúa Odriozola, E./ Amor Andrés, P. J./ Corral Gargallo, P. de, "Hombres violentos contra la pareja: trastornos mentales y perfiles tipológicos", Pensamiento Psicológico, núm. 13, 2009, pp. 27-36.
} 
Se empieza identificando a los sujetos más violentos, se les califica de "maltratadores" y se analiza retrospectivamente la escalada de la violencia como un fenómeno que se considera inevitable, hasta llegar a un punto insoportable que incluye en ocasiones la muerte de la víctima. De esta forma se refuerza la presunción general de que toda la violencia de género presenta la misma evolución y que todos los maltratadores tienen un mismo tipo de personalidad. El resultado es que se legisla para los casos más graves, olvidando que existen importantes diferencias de gravedad y de periodicidad de los incidentes, además de una gran variedad de explicaciones sobre el origen de la conducta violenta y sobre las formas de enfrentarla. ${ }^{48}$

Por tanto, antes de empezar a hablar de tratamientos es necesario conocer la multiplicidad de factores explicativos de la conducta violenta del hombre en la pareja y la fenomenología de la violencia de género. Posiblemente no exista un tratamiento, sino que la multiplicidad de causas y de tipologías de maltratadores deba corresponderse con una multiplicidad de tratamientos.

Se ha dicho que estos programas sólo ayudan a los penados que están motivados para cambiar sus pautas de comportamiento ${ }^{49}$, por lo que la imposición de la participación obligatoria en ellos como regla de conducta sería contraproducente. Frente a ello, sin dejar de reconocer que la obligación de participar impuesta a los penados que expresen su voluntad en contra puede traer consecuencias indeseables $^{50}$, se apunta que sólo así se garantiza la asistencia y, por

\footnotetext{
48 Sobre esta cuestión vid. Corvo, K./ Johnson, P. J., "Vilification of the "batterer": How blame shapes domestic violence policy and interventions", Aggression and Violent Behavior, 8, 2003, pp. 259 ss., quienes destacan que la creencia general en que la violencia aumentará con el tiempo responde a las observaciones de los trabajadores sociales de las casas de acogida, que atienden los casos más graves. Se olvida la enorme variedad en la fenomenología del maltrato.

${ }^{49}$ Como apunta Medina Ariza, J., "El tratamiento del maltratador en el contexto comunitario como respuesta penal: Consideraciones político criminales", en AA.VV., La ley de medidas de protección contra la violencia de género, Cuadernos penales José María Lidón, núm. 2, Universidad de Deusto, Bilbao, 2005, pp. 205-206, "no cabe duda de que aquellos delincuentes que a nivel cognitivo conciben la posibilidad de cambiar y tienen un deseo de hacerlo presentan un mejor pronóstico". Señala que las tasas de éxito en pacientes derivados del juzgado y sometidos obligatoriamente a tratamiento son muy bajas Echeburúa, E./ Amor, P. J., "Hombres violentos en el hogar: perfil psicopatológico y programas de intervención", en Rechea Alberola, C. (Dir.), La criminología aplicada II, Cuadernos de Derecho Judicial VII-1998, CGPJ, Madrid, 1999, pp. 118-119, quienes reconocen, no obstante, que "la negación -total o parcial- del problema dificulta la búsqueda de ayuda terapéutica", por lo que "el miedo a las repercusiones legales, puede actuar como un revulsivo", si bien esto supone que "no hay una motivación apropiada y la implicación en el cambio de conducta es escasa y fluctuante".

${ }^{50}$ No es de esperar una alta tasa de abandono, debido a que supondría la revocación de la suspensión de la ejecución de la pena de prisión, pero sí una actitud refractaria al tratamiento que dificultará obtener resultados positivos. Echeburúa, E./ Fernández-Montalvo, J., "Hombres maltratadores", en Echeburúa Odriozola, E./ Corral, P. de, Manual de violencia familiar, Siglo XXI, Madrid, 1999, p. 87, señalan que "las tasas de éxito de los pacientes derivados del juzgado o sometidos obligatoriamente a tratamiento son muy bajas", pues "en estos casos el maltratador no
} 
Faraldo - Suspensión y sustitución de las penas privativas de libertad...

tanto, sólo así existe la posibilidad de hacerles ver la necesidad de efectuar cambios en su vida y en su comportamiento. ${ }^{51} \mathrm{Y}$ de algunos estudios empíricos realizados en otros países se desprende que "aquellos hombres que completaron con éxito un programa de tratamiento presentan una mayor probabilidad de reducir la violencia y el comportamiento controlador que los hombres sancionados de otra manera", aunque el tratamiento fuera obligatorio. ${ }^{52}$ Ahora bien, la efectividad del tratamiento también se relaciona con el hecho de que se lleve a cabo en libertad, y no dentro de la prisión, por lo que la suspensión de la ejecución de la pena de prisión combinada con un programa de tratamiento dirigido específicamente al maltratador ${ }^{53}$ o a los dos miembros de la pareja ${ }^{54}$-en este último caso cuando la

tiene una motivación genuina para que se produzca un cambio sustancial en su comportamiento", citando a Madina, J., "Perfil psicosocial y tratamiento del hombre violento con su pareja en el hogar", en Echeburúa, E., y otros, Personalidades violentas, Pirámide, Madrid, 1998, p. 158.

51 En lo concerniente a la voluntariedad o no de los programas de tratamiento, la mayoría de la doctrina se decanta por una postura realista que parte de que muchos agresores no reconocen la existencia del problema y no tienen una motivación intrínseca para cambiar su conducta, por lo que no parece en absoluto inadecuado darles una motivación extrínseca, como puede ser la concesión de la suspensión acompañada como regla de conducta del sometimiento a un programa específico. Así, Benítez Jiménez, M. J., "Violencia intrafamiliar: la mujer maltratada", en Rechea Alberola, C. (Dir.), La criminología aplicada II, Cuadernos de Derecho Judicial VII-1998, CGPJ, Madrid, 1999, pp. 291-292; o Madina, J., "Perfil psicosocial y tratamiento del hombre violento con su pareja en el hogar", en Echeburúa, E. (Ed.) Personalidades violentas, Pirámide, Madrid, 1994, p. 158, quien advierte que "la mayoría de los hombres violentos jamás reconocerán su problema y consecuentemente carecen de la mínima motivación para aceptar una terapia psicológica de forma voluntaria", motivo por el cual "el tratamiento a maltratadores se inscribe dentro de lo que se ha venido en llamar terapias coactivas". En los países anglosajones ya se apuntaba esto en los años setenta. Vid. por todos, Martin, D., "Battered Women: Society's Problem”, en Roberts Chapman, J./ Gates, M. (Eds.), The victimization of women, Beverly Hills/London, Sage, 1978, p. 135. A favor de que el tratamiento sea un sustitutivo de la pena privativa de libertad que sólo se imponga si se asume voluntariamente Grupo de Estudios de Política Criminal, Una propuesta alternativa al sistema de penas y su ejecución, y a las medidas cautelares personales, Málaga, 2005, pp. 43-44.

52 Dobash, R. P./ Dobash, R. E., "Efectividad de los programas penales de tratamiento de maltratadores", en Cid Moliné, J./ Larrauri Pijoán, E. (Coords.), La delincuencia violenta. ¿Prevenir, castigar o rehabilitar?, Tirant lo Blanch, Valencia, 2005, p. 156. A este estudio y a otros parecidos se les reprocha que se basen en un número demasiado bajo de sujetos sometidos a observación y en autoinformes de los propios agresores, sin ofrecer un seguimiento consistente de los casos. Así, Eadie, T./ Knight, C., "Domestic Violence Programmes", cit., p. 176. En España vid. la amplia información bibliográfica que ofrece Medina, J. J., Violencia contra la mujer en la pareja, cit., pp. 509 ss. Cauta, Roig Torres, M., "La suspensión y la sustitución”, cit., pp. 130-131. También resulta interesante Gondolf, E. W., "Evaluating batterer counseling programs", cit., pp. 617 ss., que ofrece estadísticas de reincidencia esperanzadoras incluso en caso de imposición coactiva de sometimiento a tratamiento a través de orden judicial.

${ }^{53}$ Parece que la terapia de grupo con agresores les ayuda a reconocer la existencia del problema, les facilita modelos de conducta y nuevas perspectivas para cambiar el comportamiento personal. Sobre los objetivos que se deben perseguir con el tratamiento del maltratador desde una perspectiva feminista, vid. Bowen, E./ Brown, L./ Gilchrist, E., "Evaluating Probation Based Offender Programmes for Domestic Violence Perpetrators: A Pro-Feminist Approach", The Howard Journal, Vol. 41, núm. 3, July 2002, pp. 225 ss., quienes sin embargo ponen de relieve que se carece de estudios fiables sobre la efectividad de estos tratamientos. 
mujer decida mantener la relación sentimental- parece una intervención más efectiva que otras posibles respuestas penales que carecen de ese enfoque específico, como podría ser centrarse únicamente en la sanción y el control, sin pretender la rehabilitación.

Hay que tener en cuenta la realidad de que un número importante de mujeres maltratadas mantienen o reemprenden la relación sentimental con los maltratadores, lo que "ha hecho pensar a algunos sectores feministas en la necesidad de dirigir una especial atención hacia los hombres" $" 55$, de forma que respetando la voluntad de la víctima se consiga disminuir el peligro que para ella supone la reanudación de la relación de pareja o su finalización definitiva. Asimismo debemos partir de la constatación de que un enfoque exclusivamente basado en medidas de protección y apoyo a la mujer no garantiza suficientemente su seguridad..$^{56}$ Por ello lo más adecuado parece la adopción de tratamientos que partiendo de la perspectiva de género fomenten que el maltratador examine su conducta y el impacto de ésta en la víctima y otras personas, acepte la necesidad de cambiar y se responsabilice de ello, sin perjuicio de otras aproximaciones más específicas en caso de que concurran drogodependencias o enfermedades mentales.

En la implementación de estos programas de rehabilitación hay que atender al Real Decreto 515/2005, de 6 de mayo, por el que se establecen las

\footnotetext{
${ }^{54}$ Son programas que abordan la agresión de manera integrada, por lo que pretenden incidir sobre todos los sujetos implicados. En España, vid. Echeburúa, E./ Fernández-Montalvo, J., "Hombres maltratadores", cit., pp. 86 ss., que señalan la importancia del tratamiento del agresor cuando la víctima continúa conviviendo con él. Sobre esta cuestión, poniendo de relieve que es muy controvertida, principalmente debido a la preocupación por la seguridad de la mujer que mantiene o reanuda su relación sentimental con el agresor, vid. Corvo, K./ Johnson, P. J., "Vilification of the 'batterer", cit., pp. 273-274. No hay que olvidar, no obstante, que parece haber consenso en que la terapia de pareja puede incrementar la seguridad de la mujer en esos casos. Vid. entre otros Peled, E./ Eisikovits, Z. C./ Enosh, G./ Winstok, Z., "Choice and empowerment for battered women who stay: toward a constructivist model”, Social Work, Vol. 45, núm. 1, 2000, pp. 9 ss.; Shamai, M., "Couple therapy with battered women and abusive men: does it have a future?", en Edleson, J. L./ Eisikovits, Z. C. (Eds.), Future interventions with battered women and their families, Sage, Thousand Oaks, 1996, pp. 201 ss. Ahora bien, el hecho de que se esté tratando conjuntamente a la pareja parece influir en una disminución de las tasas de abandono del tratamiento en libertad. Vid. al respecto, Echeburúa, E., y otros, "Variables predictoras del rechazo, abandono y fracaso terapéutico en hombres violentos contra su pareja tratados psicológicamente en un marco comunitario", International Journal of Clinic and Health Psicology, Vol. 10, núm. 3, 2010, pp. 403 ss.

55 Bodelón González, E., "Género y sistema penal”, cit., p. 480. Vid. también Larrauri Pijoán, E., “Es posible el tratamiento de los agresores de violencia doméstica?”, cit., p. 363; Medina, J. J., Violencia contra la mujer en la pareja, cit., p. 504. En la literatura anglosajona, entre otros, vid. Eadie, T./ Knight, C., "Domestic Violence Programmes", cit., p. 168; Hoyle, C./ Sanders, A., "Police Response to Domestic Violence: From Victim Choice to Victim Empowerment?", British Journal of Criminology, Vol. 40, núm. 1, 2000, p. 33.

${ }^{56}$ Cfr. Lewis, R., "Making Justice Work", British Journal of Criminology, Vol. 44, núm. 2, 2004, p. 206. En España, por todos, Mata y Martín, R. M., "Modificaciones jurídico-penales”, cit., p. 56.
} 
Faraldo - Suspensión y sustitución de las penas privativas de libertad...

circunstancias de ejecución de las penas de trabajos en beneficio de la comunidad y de localización permanente, de determinadas medidas de seguridad, así como la suspensión de la ejecución de las penas privativas de libertad ${ }^{57}$, que regula la actuación de los servicios sociales penitenciarios en la aplicación de medidas alternativas a la prisión, lo que supone un primer paso hacia la creación de una infraestructura que se encargue de la gestión de estos programas en el marco de las alternativas a la pena privativa de libertad. Pero para que funcione habrá de superarse la falta crónica de recursos en el desarrollo de las medidas alternativas a la prisión, reiteradamente denunciada por la doctrina. ${ }^{58}$

La regulación contenida en el Real Decreto 515/2005 plantea ciertas dudas. El art. 16 apunta que la resolución judicial determinará las condiciones de cumplimiento de la suspensión, mientras que el art. 17 señala que serán los Servicios Sociales Penitenciarios del lugar donde el penado tenga fijada su residencia los que, tras el estudio de la situación del penado, mediante el análisis de la documentación, la entrevista con aquél y la información recibida de los centros o servicios donde realiza o va a realizar el tratamiento o programa, diseñarán el plan individual de intervención y seguimiento, que será elevado al juez o tribunal sentenciador para su aprobación o rectificación. "El juez se encuentra en la esquizofrénica situación de tener que determinar qué condiciones vincular a la suspensión, en función, explícitamente, de la peligrosidad del penado e, implícitamente, de sus necesidades de resocialización; pero la información relativa a estas dimensiones realmente no le llegará hasta que las condiciones ya han sido determinadas y los Servicios Sociales Penitenciarios han tenido la oportunidad de valorar tanto la peligrosidad como las necesidades psicosociales del penado. Mientras que los Servicios Sociales Penitenciarios, por su parte, de forma frustrante tendrán que desarrollar un plan de intervención determinado por las condiciones impuestas por el juez, que quizás sería muy diferente del que ellos habrían recomendado en función de la peligrosidad del penado y de sus necesidades psicosociales o de las condiciones que el propio juez habría impuesto de haber contado con información sobre estas dimensiones". ${ }^{99}$ En efecto, no está

\footnotetext{
${ }^{57}$ Modificado por el Real Decreto 1849/2009, de 4 de diciembre.

58 Cfr. Medina Ariza, J., "El tratamiento al maltratador", cit., pp. 189-190, 195, 206, quien pone de relieve que el resultado es que delincuentes que en otros contextos más punitivos no irían a prisión, en España sí van, ante la inexistencia de los medios necesarios para aprovechar las posibilidades creadas en el Código Penal de 1995.

59 Medina Ariza, J., "El tratamiento al maltratador", cit., p. 196. El juez o tribunal debería poder disponer de un tiempo de atención terapéutica que permitiera la evaluación del agresor por un equipo interdisciplinario, el cual propondría la intervención que se estimara más adecuada para el perfil del agresor, derivándolo a un centro de tratamiento para el maltrato, en el que personal especializado realizaría la intervención. Así lo proponen Redondo Illescas, S./ Garrido Genovés, V., "Propuesta para el tratamiento en la comunidad de los agresores interfamiliares. Propuesta desarrollada a petición del Consejo General del Poder Judicial para la discusión de la misma en la Comisión Interinstitucional creada al efecto", 21 de mayo de 1999, disponible en http://www.observatorioviolencia.org/Upload/DOC68_MALTRATADORESFAMILIARES.pdf, p. 21.
} 
previsto que el juez o tribunal pueda revisar las reglas de conducta impuestas una vez recibido el plan y la valoración del penado realizados por los Servicios Sociales Penitenciarios en cumplimiento de lo dispuesto en el art. 17 del Real Decreto 515/2005. La única posibilidad de sustituir la regla de conducta impuesta por otra distinta es que el sujeto infrinja durante el plazo de suspensión las obligaciones o deberes impuestos, con la excepción de que se trate de un condenado por delitos relacionados con la violencia de género, en cuyo caso, como hemos visto, sólo cabe la revocación de la suspensión de la ejecución de la pena (art. $84 \mathrm{CP}$ ).

El incumplimiento de cualquiera de las obligaciones o deberes impuestos como reglas de conducta se sanciona con la revocación de la suspensión en todo caso, lo que no parece adecuado ${ }^{60}$, en particular porque no se tienen en cuenta las circunstancias del caso, qué regla se incumple, si el incumplimiento está justificado o no, si es reiterado, si es intencionado, si ha supuesto un peligro para la víctima, si se debe a una invitación de la víctima... Tratándose de la obligación de asistir a programas de rehabilitación, sin dejar de reconocer el importante efecto preventivo de la amenaza de revocación de la suspensión ${ }^{61}$, podrían contemplarse otras medidas dirigidas a garantizar la asistencia ${ }^{62}$ como, por ejemplo, imponer una fianza que se perdería en caso de incumplimiento, que se aplicarían antes de la revocación.

El art. 84.3 CP no regula la tramitación que el órgano judicial ha de seguir para acordar la revocación de la suspensión ante el incumplimiento de las

\footnotetext{
${ }^{60}$ Críticos, Puente Segura, L., Suspensión, cit., pp. 155-156 y 159; Sanz Mulas, N., Alternativas, cit., pp. 301 ss.; la misma autora en Sanz Mulas, N., y otros (Coords.), Ley de Medidas, cit., p. 160. Apunta que "debe abrirse un trámite de audiencia, y puede no ser inhabitual que existan discrepancias sobre si ha existido o no incumplimiento del deber", Ceres Montes, J. F., "Las reformas penales", cit., p. 298. En las Reglas mínimas de las Naciones Unidas sobre las medidas no privativas de libertad (Reglas de Tokio), R 45/110, de 14 de diciembre de 1990, se señala que "el fracaso de una medida no privativa de la libertad no significará automáticamente la imposición de una medida privativa de la libertad” (Regla 14.3), y que “en caso de modificación o revocación de la medida no privativa de la libertad, la autoridad competente intentará imponer una medida sustitutiva no privativa de la libertad que sea adecuada. Sólo se podrá imponer la pena de prisión cuando no haya otras medidas sustitutivas adecuadas" (Regla 14.4).

${ }^{61} \mathrm{La}$ doctrina apunta la necesidad de que la alternativa sea lo suficientemente disuasoria como para que el agresor opte por el tratamiento, pues en general se trata de sujetos poco motivados a cambiar su comportamiento agresivo. Vid. Madina, J., "Perfil psicosocial", cit., p. 158.

62 También hay propuestas para que se tenga en cuenta no sólo la asistencia, sino el cumplimiento de una serie de criterios, entre los que se encuentran no acudir bajo la influencia de drogas o alcohol, aceptar la violencia como un problema, comportarse de manera apropiada en las sesiones, participar activamente, conocer las técnicas que se enseñen, etc. Cfr. Hamby, S., "Partner Violence: Prevention and Intervention", en Jasinski, J./ Williams, L. (Eds.), Partner Violence: A Comprehensive Review of 20 Years of Research, Newbury Park, Sage, 1998, pp. 231-232. En España propone que la falta de aprovechamiento se considere incumplimiento de la regla impuesta Íñigo Corroza en Muerza Esparza (Coord.), Comentario, cit., p. 30. En contra, con razón, Mata y Martín, R. M., "Modificaciones jurídico-penales", cit., p. 57, que apunta que "no se puede obligar a resultados, por otra parte difíciles de precisar".
} 
Faraldo - Suspensión y sustitución de las penas privativas de libertad...

obligaciones o deberes a los que se refiere. El respeto del derecho de defensa y la identidad de la consecuencia prevista en este apartado con la última del número anterior (art. 84.2 c) CP) obliga a exigir en ambos casos idénticos requisitos, concretados en la concesión de audiencia de las partes y decisión mediante auto. Así se apunta en la Circular 1/2005, de 31 de marzo, de la Fiscalía General del Estado.

Además, y a diferencia de lo previsto en la sustitución de la pena, no se prevé el abono o compensación parcial de la pena de prisión si se produce la revocación habiendo cumplido el sujeto parcial o totalmente las reglas de conducta impuestas. Sería deseable introducir una previsión expresa conforme a la cual si la suspensión llega a revocarse, la pena impuesta deberá tenerse por ejecutada en aquella parte que se estime compensada. ${ }^{63}$

Queda por determinar una cuestión importante, como es el efecto que debe tener la comprobación de que el condenado delinquió o incumplió las reglas de conducta impuestas cuando ya se ha producido la remisión de la pena por cumplimiento del plazo de suspensión.

La Ley de Condena Condicional, de 17 de marzo de 1908, disponía en su art. 14 el cumplimiento de la pena suspendida cuando el reo fuese condenado después del plazo de suspensión por un hecho cometido dentro de dicho plazo, salvo el caso de prescripción. El Código Penal de 1995 no recogió un precepto semejante, pero la jurisprudencia ha venido sosteniendo que se debe ejecutar la pena suspendida en el entendimiento de que el auto de remisión está sometido a la condición resolutoria de no haber delinquido durante el plazo de suspensión. A ello se añade que los arts. 84.1 y 3 y $85.1 \mathrm{CP}$ señalan imperativamente que "si el sujeto delinquiera durante el plazo de suspensión fijado, el Juez o Tribunal revocará la suspensión de la ejecución de la pena", que "en el supuesto de que la pena suspendida fuera de prisión por la comisión de delitos relacionados con la violencia de género, el incumplimiento por parte del reo de las obligaciones o deberes previstos en las reglas $1^{\mathrm{a}}, 2^{\mathrm{a}}$ y $5^{\mathrm{a}}$ del apartado 1 del artículo 83 determinará la revocación de la suspensión de la ejecución de la pena", y que "revocada la suspensión, se ordenará la ejecución de la pena", sin exceptuar de este mandato el caso de que se hubiera dictado auto de remisión. ${ }^{64}$

\footnotetext{
63 Así, Sánchez Yllera en Vives Antón, T. S. (Coord.), Comentarios al Código Penal de 1995. Volumen I (Articulos 1 a 233), Tirant lo Blanch, Valencia, 1996, p. 488; Sanz Mulas, N., Alternativas, cit., p. 292. Considera posible interpretar la regulación actual en este sentido, con base en el principio de proporcionalidad y en la proximidad sustantiva y teleológica entre la suspensión y la sustitución, Cardenal Montraveta, S., “Alternativas a la pena de prisión. Especial consideración de la suspensión de la ejecución y la sustitución", en Mir Puig, S./ Corcoy Bidasolo, M. (Dirs.), Nuevas tendencias en política criminal. Una auditoría al Código Penal español de 1995, Julio César Faira - Editor, Montevideo-Buenos Aires, 2006, pp. 39-40.

${ }^{64}$ En este sentido, vid. el apartado XIII.5.b de la Circular 1/2005, de 31 de marzo, de la Fiscalía General del Estado.
} 


\section{El régimen especial de sustitución de la pena de prisión}

$\mathrm{El}$ art. $88 \mathrm{CP}$ regula los requisitos para la sustitución de las penas de prisión que no excedan de un año, y excepcionalmente que no excedan de dos, por multa o por trabajos en beneficio de la comunidad, y en los casos de penas de prisión que no excedan de seis meses, también por localización permanente. El art. 88.1 CP señala en su último párrafo que "en el caso de que el reo hubiera sido condenado por un delito relacionado con la violencia de género, la pena de prisión sólo podrá ser sustituida por la de trabajos en beneficio de la comunidad o localización permanente en lugar distinto y separado del domicilio de la víctima". ${ }^{65}$

Esta redacción es fruto de varias modificaciones. Así, la LO 1/2004, de 28 de diciembre, de protección integral contra la violencia de género modificó el régimen especial de sustitución que había sido introducido por la LO 15/2003, que se refería simplemente a los casos de condena por el delito recogido en el art. 173.2 CP, prohibiendo sustituir la pena de prisión por multa, debiendo emplearse siempre como pena sustitutiva la de trabajos en beneficio de la comunidad, estando obligado el juez o tribunal a imponer dos reglas de conducta, la sujeción a programas específicos de reeducación y tratamiento psicológico y la prohibición de acudir a determinados lugares (artículo $88 \mathrm{CP}$ ).

Sobre la sustitución de la alusión al art. 173.2 CP por "delito relacionado con la violencia de género" y el alcance de esta expresión baste la remisión a lo indicado supra.

En segundo lugar, la LO 5/2010, de 22 de junio, añade como pena sustitutiva que puede ser empleada en la sustitución de la pena de prisión impuesta a condenados por violencia de género la localización permanente, respecto de la cual se puntualiza que ha de cumplirse "en lugar distinto y separado del domicilio de la víctima”.

La explicación de este régimen especial para condenados por delitos relacionados con la violencia de género es multifactorial. Así, en primer lugar, el que se impida sustituir la pena de prisión por la multa tiene su fundamento en la tutela de los intereses (económicos) de la víctima: la multa afectaría a la capacidad económica de la unidad familiar, y no sólo al autor, de ahí que no se considere adecuado imponerla en estos casos. ${ }^{66}$

\footnotetext{
65 Cabe preguntarse si esta regulación es una excepción a la posibilidad de sustituir las penas privativas de libertad inferiores a seis años impuestas a un extranjero no residente legalmente en España por su expulsión del territorio español, prevista en el art. 89 CP. Roig Torres, M., "La suspensión y la sustitución”, cit., p. 129, entiende que no, pero a mi juicio la cuestión está abierta. ${ }^{66}$ Vid. entre otros, Acale Sánchez, M., La discriminación, cit., p. 343; Blay Gil, E., "El trabajo en beneficio de la comunidad como pena para la violencia familiar", Revista de Derecho Penal y Criminología, núm. 19, 2007, pp. 408 ss., quien señala también que la multa podría afectar al abono de las pensiones compensatorias o alimenticias, pudiendo incluso dar lugar al embargo de la vivienda familiar (p. 408, nota núm. 16); Larrauri Pijoán, E., “¿Es posible el tratamiento de los
} 
Faraldo - Suspensión y sustitución de las penas privativas de libertad...

Resulta evidente que esta justificación parte de la tradicional visión de la mujer como económicamente dependiente del hombre, sin tener en cuenta que puede existir violencia de género contra una mujer económicamente independiente, perpetuando así un prejuicio tradicional.

También se puede pensar que al limitar el arbitrio judicial, eliminando la posibilidad de elección entre multa y trabajos en beneficio de la comunidad prevista en el régimen general de sustitución, se pretenden mejorar las posibilidades de resocialización del condenado, pues el trabajo en beneficio de la comunidad puede tener un efecto más rehabilitador que el pago de una multa" "si bien podría aseverarse que eso ya está de alguna manera previsto en el propio precepto donde se obliga, además, a la 'sujeción a programas específicos de reeducación y tratamiento psicológico"' ${ }^{68}$ Sin embargo, el hecho de que a partir de la entrada en vigor de la LO $5 / 2010$ se contemple como alternativa a los trabajos la localización permanente, que carece de cualquier ínfula resocializadora, priva de apoyos a esta postura.

Por su parte, la previsión de una alternativa a la pena de trabajos en beneficio de la comunidad tiene en cuenta, por fin, que esta pena sólo puede imponerse con el consentimiento del penado, según dispone el art. $49 \mathrm{CP}$, consentimiento que deja de responder a una voluntad real cuando la única alternativa es el cumplimiento de la pena privativa de libertad originariamente impuesta, y no de otra pena de distinta

agresores de violencia doméstica?", cit., p. 377; Medina Ariza, J., "El tratamiento al maltratador", cit., p. 199; Puente Segura, L., Suspensión, cit., p. 328. Antes de la reforma señalaba que pedir penas de multa era algo que habría de producir desazón en las víctimas Merlos Chicharro, J. A., "Algunas cuestiones de las diligencias de prueba. Las frecuentes retractaciones de la víctima. La protección de la víctima en el proceso", en AA.VV., Estudios sobre violencia familiar y agresiones sexuales. II 2000. Violencia física y psíquica en el ámbito familiar (1 ${ }^{a}$ reunión de Fiscales encargados del Servicio de Violencia Familiar). Violencia habitual en el ámbito familiar, Ministerio de Justicia/ Ministerio de Trabajo y Asuntos Sociales, Madrid, 2000, p. 88.

${ }^{67}$ Sobre el efecto resocializador de la pena de trabajos en beneficio de la comunidad y sus límites, vid. ampliamente Brandariz García, J. A., El trabajo en beneficio de la comunidad como sanción penal, Tirant lo Blanch, Valencia, 2002, pp. 80 ss.; en relación con el tema que nos ocupa, del mismo autor, "La sanción de trabajos en beneficio de la comunidad como respuesta a la violencia de género", en Puente Aba, L. M. (Dir.), La respuesta penal a la violencia de género. Lecciones de diez años de experiencia de una política criminal punitivista, Comares, Granada, 2010, pp. 213 ss. Manifiesta cierta desconfianza sobre el "presunto efecto resocializador" del trabajo en beneficio de la comunidad para los condenados por violencia de género Roig Torres, M., "La suspensión y la sustitución”, cit., pp. 128-129; también Torres Rosell, N., "Las sanciones penales en la lucha contra la violencia de género", en Villacampa Estiarte, C. (Coord.), Violencia de género y sistema de justicia penal, Tirant lo Blanch, Valencia, 2008, pp. 238 ss. Entiende que el trabajo "asegura, o cuando menos facilita, el control que pueda realizarse respecto de" la persona del condenado, Puente Segura, L., Suspensión, cit., p. 328.

${ }^{68}$ Sanz Mulas en Sanz Mulas, N./ González Bustos, M. A./ Martínez Gallego, E. M. (Coords.), Ley de Medidas, cit., p. 161. 
naturaleza ${ }^{69}$, como ocurría antes de la reforma introducida por la LO 5/2010, lo que no sólo suponía un tratamiento desigual de los condenados por delitos relacionados con la violencia de género respecto de otros delincuentes que no encontraba una explicación convincente, sino que ponía en peligro las expectativas de resocialización que suscita esta pena. ${ }^{70}$

La reforma de 2010 no se aprovechó para aclarar si la limitación de un año en la duración de la pena de trabajos en beneficio de la comunidad que establece el art. 40.4 CP es aplicable a todos los supuestos de trabajos sustitutivos. En la actualidad hay que entender que sólo pueden sustituirse por trabajos las penas de prisión de hasta un año de duración, cuando en el régimen general excepcionalmente pueden sustituirse las penas de prisión de hasta dos años. Y es que aunque la Circular 2/2004, de 25 de noviembre, de la Fiscalía General del Estado, admita que se pueda superar el límite de un año ${ }^{71}$, "una sanción de TBC sustitutiva que puede extenderse hasta 730 días o 5840 horas es un desatino político-criminal", tanto desde la perspectiva de su falta de proporcionalidad con el hecho delictivo que motiva su imposición como por las dificultades de una ejecución tan larga, lo que conlleva serios riesgos de incumplimiento. $^{72}$

En cualquier caso, el éxito de esta pena sustitutiva depende en buena medida de su aceptación por parte de los operadores jurídicos y del resto de la ciudadanía ${ }^{73}$, incluyendo los grupos de apoyo a las víctimas de la violencia de género.

\footnotetext{
${ }^{69}$ Se ha reconocido en la doctrina que el hecho de que en el régimen general en ausencia del consentimiento se deba afrontar el cumplimiento de la pena de multa o, si no les posible pagarla, de la pena privativa de libertad originalmente impuesta "no deja de suponer una cierta presión en el proceso de formación de la voluntad del penado", descartándose establecer requisitos estrictos de voluntariedad o espontaneidad en la aceptación del condenado, bastando una simple conformidad. Brandariz García, J. A., El trabajo, cit., pp. 212-213; del mismo autor, "La sanción”, cit., p. 228. Vid. también Tamarit Sumalla, J. M., "La sustitución de las penas de prisión”, en Álvarez García, F. J./ González Cussac, J. L. (Dirs.), Comentarios a la Reforma Penal de 2010, Tirant lo Blanch, Valencia, 2010, p. 129. Y es que el sentido fundamental de la previsión de este requisito es evitar la colisión con el art. 25.2 CE, que prohíbe los trabajos forzados, si bien no se olvida que la orientación resocializadora de esta pena depende fundamentalmente de la cooperación del penado. Sobre ello vid. ya Asúa Batarrita, A., "El trabajo al servicio de la comunidad como alternativa a otras penas", Estudios de Deusto 1984, p. 324; Brandariz García, J. A., op. cit., p. 222; Sanz Mulas, N., Alternativas, cit., p. 346. En relación con la discutida "libertad" en la decisión individual de aceptar el trabajo, vid. Cuesta Arzamendi, J. L. de la, "La sanción de trabajo en provecho de la comunidad", La Ley 1985-2, p. 1071.

${ }^{70}$ Cfr. Brandariz García, J. A., El trabajo, cit., p. 90.

${ }^{71}$ Opción que critica, con razón, Torres Rosell, N., "Las sanciones", cit., p. 233.

72 Brandariz García, J. A., "La sanción”, cit., pp. 228-229. Vid. también Puente Segura, L., Suspensión, cit., pp. 328-329, aunque admite que se puede superar el año.

${ }^{73}$ Cfr. Bueno Arús, F., "Community Service and Spanish Law", en AA.VV., Community Service as an Alternative to the Prison Sentence, International Penal and Penitentiary Foundation, Bonn, 1987, p. 59; Pozuelo Pérez, L., "La pena de trabajos beneficio de la comunidad", ICADE sept-dic. 1997, pp. 338-339; Sanz Mulas, N., Alternativas, cit., p. 350.
} 
Faraldo - Suspensión y sustitución de las penas privativas de libertad...

El aumento más bien brusco que se puede apreciar en su nivel de aplicación desde 2004 se debe tanto a su utilización en el ámbito delictivo objeto de este estudio como a su extensión a los delitos contra la seguridad vial. Sin embargo, la ejecución efectiva sigue siendo problemática. ${ }^{74}$

En cuanto a la localización permanente, cabe aplaudir su previsión como alternativa a los trabajos por el motivo ya expuesto. En sí misma considerada, no obstante, no merece un juicio muy positivo, por su carencia de efectos resocializadores.

El Consejo General del Poder Judicial también la critica, pero por su falta de eficacia intimidatoria: "No se entiende acertado, sin embargo, acudir en la lucha contra la violencia de género a una medida que no provoca en el agresor casi ningún tipo de eficacia sancionadora al quedar reducida la pena a permanecer en el lugar indicado. Parece, frente a ello, preferible volver a la anterior redacción, que permitía exclusivamente la sustitución de la pena de prisión por la de trabajos en beneficio de la comunidad, obligando al penado a llevar a cabo trabajos sociales tendentes a rehabilitarle de su conducta". ${ }^{75}$

La alusión expresa que la ley hace a que se cumpla "en lugar distinto y separado del domicilio de la víctima" es redundante, visto que es obligatoria la aplicación de las prohibiciones de aproximación y comunicación con la víctima como reglas de conducta. ${ }^{76}$

Por lo demás, no queda claro si la limitación de la localización permanente como pena sustitutiva de las penas de prisión de hasta seis meses en el régimen general alcanza también al especial para la violencia de género.

Añade el art. 88.1 CP que "en estos supuestos, el Juez o Tribunal impondrá adicionalmente, además de la sujeción a programas específicos de reeducación y tratamiento psicológico, la observancia de las obligaciones o deberes previstos en las reglas $1^{\mathrm{a}}$ y $2^{\mathrm{a}}$, del apartado 1 del artículo 83 de este Código”. Obsérvese que se trata de nuevo de la imposición imperativa de las obligaciones o deberes de prohibición de acercamiento a determinados lugares y personas, que se suele justificar en la necesidad de proteger a la víctima o a terceros. Pero si necesitan protección es porque el condenado es peligroso, lo que contradice el fundamento de la concesión de la sustitución.

No se incluye, como sí se hace en la suspensión, la necesidad de imponer la obligación recogida en la regla $5^{\mathrm{a}}$, pues ya se hace referencia a la "sujeción a

\footnotetext{
${ }^{74}$ Vid. los datos que ofrece Brandariz García, J. A., "La sanción”, cit., p. 225, nota núm. 28. Señala también estos problemas Torres Rosell, N., "Las sanciones", cit., p. 240.

${ }^{75}$ Informe, cit., p. 12.

${ }^{76}$ Lo apunta también Tamarit Sumalla, J. M., “La sustitución”, cit., p. 129.
} 
programas específicos de reeducación y tratamiento psicológico" en el mismo art. 88.1.3 ${ }^{\circ} \mathrm{CP}$.

En cualquier caso, la aplicación conjunta de una pena sustitutiva de trabajos en beneficio de la comunidad o de una localización permanente y de la obligación de someterse a programas específicos de reeducación y tratamiento psicológico permite ofrecer una verdadera alternativa a la privación de libertad ${ }^{77}$, que posibilita incidir en las causas del maltrato.

El art. 7.3 del Real Decreto 515/2005 señala al respecto que "en el supuesto de sustitución regulado en el artículo 88.1 del Código Penal, si se le impusiera, junto a la pena de trabajos en beneficio de la comunidad, la obligación de seguir un programa específico de reeducación y tratamiento psicológico, los Servicios Sociales Penitenciarios remitirán al penado al centro, institución o servicio específico para la realización de dicho programa, de forma compatible con el cumplimiento de la pena, y realizarán el pertinente seguimiento del programa del que informarán oportunamente al juez de vigilancia penitenciaria”.

Ante la ausencia de otras referencias a los programas específicos de reeducación y tratamiento psicológico, así como a la acreditación que se pueda exigir a las personas o entidades que los desarrollen, la Circular 1/2005, de 31 de marzo, de la Fiscalía General del Estado, señala que los fiscales "valorarán prudencialmente la posibilidad de reclamar de los médicos forenses o de los servicios sociales correspondientes los informes necesarios para poder informar adecuadamente acerca de tales programas" (apartado XIV.4), indicación que reitera en la Circular 4/2005, de 18 de julio (apartado IV.H).

En lo que respecta al control del cumplimiento de la pena sustitutiva de trabajos en beneficio de la comunidad, se aplica el art. 7.2 del Real Decreto 515/2005. Ahora bien, no queda claro si en caso de tener que revocar la pena sustitutiva de trabajos por incumplimiento debe descontarse de la pena de prisión inicialmente impuesta la parte de tiempo a que equivalgan las jornadas realizadas, de acuerdo con la regla de conversión que establece que un día de prisión es equivalente a una jornada de trabajo. El art. 88.2 CP alude únicamente al abono "de las cuotas satisfechas", lo que evidentemente se refiere al abono de las cuotas de multa, pero no abonar las jornadas de trabajo (o, cabe añadir, los días de localización permanente) es una solución injusta completamente carente de fundamento. ${ }^{78}$ Para paliarla, se

\footnotetext{
${ }^{77}$ En torno a la combinación de trabajo en beneficio de la comunidad y orden de tratamiento, vid. en sentido muy positivo, si bien reconociendo que todavía no hay datos empíricos, Johnson, C./ Rex, S., “Community Service: Rediscovering Reintegration", en Ward, D., y otros (Eds.): Probation. Working for Justice, $2^{a}$ ed. Oxford University Press, Oxford, 2002, pp. 199-200. En España, Blay Gil, E., "El trabajo”, cit., pp. 403 y 414; Brandariz García, J. A., “La sanción”, cit., p. 231.

${ }^{78}$ En este sentido Brandariz García, J. A., El trabajo, cit., pp. 322 ss., con información acerca de la situación en Derecho comparado; Roig Torres, M., "La suspensión y la sustitución”, cit., p. 131; Téllez Aguilera, A., "La reforma del Código Penal y sus implicaciones penológicas", La Ley Penal núm.1, año I, enero 2004, p. 35.
} 
Faraldo - Suspensión y sustitución de las penas privativas de libertad...

propone en la doctrina que en este ámbito delictivo se valore con especial cautela el incumplimiento, "aprovechando las alternativas que como cumplimiento defectuoso dispone el art. 49.6 CP”. $^{79}$

Como hemos visto, el art. $49 \mathrm{CP}$ señala que en caso de que aprecie un incumplimiento el juez de vigilancia penitenciaria deberá deducir, además, testimonio por delito de quebrantamiento de condena (art. $468 \mathrm{CP}$ ), que alcanza a toda "condena, medida de seguridad, prisión, medida cautelar, conducción o custodia". En mi opinión la revocación de la sustitución por incumplimiento no es compatible con un delito de quebrantamiento de condena, pues la regulación del art. $88 \mathrm{CP}$, en tanto prevé una disciplina propia del incumplimiento, que sanciona con la revocación de la sustitución, desplaza al art. $468 \mathrm{CP}^{80} \mathrm{La}$ compatibilidad de ambas consecuencias sancionadoras supondría vulnerar el principio "non bis in idem", constituyendo a todas luces una reacción excesiva.

El Código Penal no atribuye ninguna consecuencia específica al incumplimiento de las reglas de conducta que hayan podido imponerse junto con la pena sustitutiva, ni distingue entre reglas de imposición obligatoria o potestativa. Según un sector doctrinal minoritario, cabe entender que se trata de un incumplimiento "en parte" de la pena sustitutiva que dará lugar a su revocación con el correspondiente regreso a la pena impuesta inicialmente. ${ }^{81}$ No parece adecuada esta solución, demasiado estricta en comparación con la regulación que se contiene en la suspensión para el caso de incumplimiento de las mismas

\footnotetext{
${ }^{79}$ Brandariz García, J. A., “La sanción”, cit., p. 230. En el mismo sentido, Blay Gil, E., "El trabajo”, cit., p. 405.

${ }^{80}$ Cfr. Brandariz García, J. A., El trabajo, cit., pp. 324 ss., con amplia información bibliográfica y detallada argumentación. En contra, el Consejo General del Poder Judicial, Informes del Consejo General del Poder Judicial sobre las Reformas Penales, CGPJ, Madrid, 2003, p. 201, donde señala que "el incumplimiento de la pena de trabajos en beneficio de la comunidad, además de motivar la ejecución de la pena privativa de libertad inicialmente impuesta, en los casos en que aquélla hubiese sido impuesta como sustitutiva, supone la realización del tipo del delito de quebrantamiento de condena del art. 468 del Código Penal".

81 Cfr. Berdugo Gómez De La Torre, J. R., "Alternativas a las penas de prisión. La libertad condicional. El tercer grado penitenciario y los problemas que plantea el art. 36 del Código Penal”, en Castellano Rausell, P. (Dir.), Las últimas reformas penales, Cuadernos de Derecho Judicial III-2005, Madrid, pp. 208-209, citando a López Lorenzo; Gracia Martín en Gracia Martín, L. (Coord.), Las consecuencias jurídicas del delito en el nuevo Código Penal español, Tirant lo Blanch, Valencia, 1996, p. 280; Sánchez Yllera en Vives Antón, T. S. (Coord.), Comentarios, I, cit., p. 502. Para López Lorenzo, V., "La suspensión y la sustitución", cit., p. 44, sólo el incumplimiento reiterado de las reglas de conducta impuestas equivale al incumplimiento de la pena sustitutiva, "por aplicación analógica de lo dispuesto en el art. 84 del CP y llevará consigo el necesario cumplimiento de la pena de prisión". Señala Llorca Ortega, J., Manual de determinación de la pena, $6^{\mathrm{a}}$ ed., Tirant lo Blanch, Valencia, 2005, p. 304, que el incumplimiento de las reglas de conducta no se puede equiparar al de la pena sustitutiva, incluso tratándose de reglas de imposición preceptiva, por lo que "no producirá, al menos necesariamente, la revocación de la sustitución", aunque admite que el juez o tribunal reconsidere su decisión.
} 
obligaciones o deberes $^{82}$, que ofrece más alternativas al órgano judicial que la mera revocación del beneficio, si bien es cierto que para condenados por violencia de género esas alternativas se eliminan, siendo obligatorio proceder a la revocación de la suspensión. A mi juicio, ante la falta de previsión de consecuencias para el incumplimiento de las reglas de conducta es necesario concluir que dicho incumplimiento no puede ser sancionado de ningún modo. ${ }^{83}$

\section{Conclusiones}

A la hora de establecer medidas penales para el control de la violencia de género no pueden ignorarse los rasgos básicos que permiten deslindar la singularidad de la violencia que padece la mujer a manos de su pareja, y muy en particular la clase de relación entre el agresor y la víctima: relación sentimental o de convivencia, actual o de pasado reciente, con o sin hijos, de intimidad afectiva y/o sexual entre dos personas adultas, con su propia dinámica de interacción en modo alguno asimilable a otras relaciones familiares. ${ }^{84}$

Piénsese que en la relación de pareja se proyectan de forma singular las representaciones sobre la propia identidad y las expectativas donde los roles de género, culturalmente transmitidos y aprendidos, juegan un papel decisivo. Las expectativas de acatamiento y sumisión de la mujer en esa relación se encuentran en la base de la violencia empleada por el varón como instrumento para reclamar el efectivo sometimiento. ${ }^{85} \mathrm{~A}$ la vez, el repliegue de la mujer ante el hostigamiento, que se explica como mecanismo de defensa dirigido a protegerse de las experiencias vividas que resultan insoportables o difíciles de sobrellevar ${ }^{86}$, y los intentos de salvar

82 Propone aplicar a la sustitución las previsiones del art. 84.2 CP, dispuestas para el incumplimiento de las condiciones en los supuestos de suspensión, Lascuraín Sánchez en Rodríguez Mourullo, G. (Dir.), Comentarios al Código Penal, Civitas, Madrid, 1997, p. 289; también Téllez Aguilera, A., Nuevas penas y medidas alternativas a la prisión, Edisofer, Madrid, 2005, p. 182, si bien puntualiza que "no estaría de más una mayor precisión del legislador al respecto". Similar Brandariz García, J. A., “La sanción”, cit., pp. 229-230, para quien "la solución más adecuada sería entender que el incumplimiento de las reglas de conducta puede determinar en algunos casos la revocación de la sustitución, pero que ello... no ha de ser siempre necesariamente así".

${ }^{83} \mathrm{La}$ Circular 1/2005, de 31 de marzo, de la Fiscalía General del Estado, reconoce esta situación de vacío legal al señalar que "por falta de respaldo legal, los Fiscales no pueden asumir iniciativa si se constata el incumplimiento de las reglas". Vid. también Roig Torres, M., "La suspensión y la sustitución”, cit., p. 130, con ulteriores citas bibliográficas. Indirectamente, Brandariz García, J. A., "La sanción", cit., p. 230.

84 Sigo a Asúa Batarrita, A., "Los nuevos delitos de 'violencia doméstica' tras la reforma de la LO 11/2003, de 29 de septiembre”, en Díez Ripollés, J. L. y otros (Eds.), Las recientes reformas penales. Algunas cuestiones, Universidad de Deusto, Bilbao, 2004, pp. 205-206. Sobre la violencia contra la pareja en contraste con otras formas de violencia vid. Lorente Acosta, M., "Síndrome de agresión", cit., pp. 5354; Medina, J. J., Violencia contra la mujer en la pareja, cit., pp. 76 ss.

${ }^{85}$ Vid. los rasgos del agresor violento en Robledo Villar, A., "Los elementos personales de la agresión familiar", en AA.VV., Estudios sobre violencia familiar y agresiones sexuales, Tomo I, Madrid, 2000, pp. 197 ss. ${ }^{86}$ Cfr. Robledo Villar, A., "Los elementos personales", cit., p. 204. 
Faraldo - Suspensión y sustitución de las penas privativas de libertad...

la relación, frecuentemente para evitar los traumas de una ruptura para los hijos comunes o para no tener que hacer frente al reproche social o familiar por ser causante de la ruptura, no son ajenos a su socialización en el modelo de género, pero tampoco son ajenos a una lógica ponderación de costes y de valoración de afectos que no puede tacharse de irracional ${ }^{87}$. El proceso de ruptura requiere un tiempo de maduración y de asunción de las consecuencias, lo que explica en muchas ocasiones el titubeo o la tardanza en la adopción de ciertas decisiones, o en denunciar los hechos cuando la situación resulta ya explosiva ${ }^{88}$, titubeo o tardanza que se ha entendido como "morbosa" ${ }^{\text {" }}$ o "lindante con el masoquismo". 90

De ello derivan ciertas características del maltrato a la mujer en la pareja que deben tenerse en cuenta en el diseño de medidas de prevención extrapenales y de pautas político-criminales de actuación. ${ }^{91}$ Evidentemente se trata en buena medida de peculiaridades asociadas a las vicisitudes de la relación de pareja, ámbito que es difícilmente compatible con la imposición por ley de una ruptura no deseada, lo cual genera un problema de imposible resolución desde parámetros estrictamente punitivos. De ahí la necesidad de una intervención más meditada que la que han operado las LO 15/2003, 1/2004 y 5/2010.

Al inicio señalé que hasta ahora se ha fracasado a la hora de entender y atender la propia ambivalencia que manifiesta la mujer a la hora de recurrir a la Administración de Justicia. Frente a la anulación de su voluntad a través de la imposición de medidas cautelares, penas, medidas de seguridad y reglas de conducta basadas en el alejamiento del agresor, que supone un tratamiento especial, necesario en este ámbito precisamente por la relación que une al autor y a la víctima, pero que parte de una imagen irracional de la mujer maltratada, hay que realizar un nuevo esfuerzo de comprensión que vaya más allá de la tutela que se ofrecería a una persona

\footnotetext{
${ }^{87}$ Cfr. Larrauri Pijoán, E., “¿Por qué retiran las mujeres maltratadas las denuncias?”, cit., pp. 299 ss.; de la misma autora, "¿Se debe proteger a la mujer contra su voluntad?”, cit., pp. 159 ss. También Asúa Batarrita, A., "Los nuevos delitos de 'violencia doméstica", cit., p. 206.

88 Cfr. Haimovich, P., "El concepto de malos tratos. Ideología y representaciones sociales", en Maquieira, V./ Sánchez, C. (compiladores), Violencia y Sociedad Patriarcal, Fundación Pablo Iglesias, Madrid, 1990, p. 103, quien señala que no todas las mujeres maltratadas se dirigen al sistema penal en busca de protección, porque la denuncia se ve como una ruptura definitiva, y puede suponer no sólo el cuestionamiento del mundo íntimo de la mujer, sino también el castigo de una persona con la que aún tiene vínculos afectivos que todavía se tiene la esperanza de recuperar.

${ }^{89}$ Como denuncia Fernández, R., "El Derecho Penal", cit., p. 195. Sobre el tema vid. Larrauri Pijoán, E., “¿Por qué retiran las mujeres maltratadas las denuncias?”, cit., pássim.

90 García Vitoria, A., "Tratamiento jurisprudencial actual de la violencia en el ámbito doméstico y familiar”, en Morillas Cueva, L. (Coord.), Estudios penales sobre violencia doméstica, Edersa, Madrid, 2002, p. 532.

91 Apuntadas por Asúa Batarrita, A., "Los nuevos delitos de 'violencia doméstica”, cit., pp. 206-207. Como pone de relieve Laurenzo Copello, P., "El modelo de protección reforzada", cit., p. 95, "cuando se reivindica un tratamiento jurídico independiente para esta clase específica de violencia no se trata sólo- de desvelar la radical injusticia que ella entraña. Se trata, sobre todo, de orientar la política legislativa hacia las auténticas causas del problema, única garantía del desarrollo de estrategias mínimamente aceptables para combatirlo".
} 
incapaz, y que sin dejar de ser un tratamiento especial ${ }^{92}$ permita reinterpretar esas medidas de protección de forma compatible con el respeto a su intimidad, derecho al que pertenece la libertad de crear, mantener y poner fin a una relación sentimental. ${ }^{93}$ En la medida en que el sistema penal sólo atienda a una lógica, la del castigo, y desatienda cualquier otra demanda de la mujer, no debe extrañar que la mujer entienda que ese sistema no la va a apoyar en lo que ella pretende conseguir ${ }^{94}$, que es el cese de la violencia, no necesariamente una separación forzosa. No toda intervención estatal que pretende favorecer a la mujer acaba redundando en una mejora de su bienestar, como nos demuestra un análisis incluso superficial de pertinencia de género.

En particular, reconociendo desde un enfoque pragmático que las "no drop policies" tienen su razón de ser y sin duda resultan necesarias en el momento de iniciación del procedimiento penal y durante su desarrollo ${ }^{95}$, también hay que ser conscientes de que la imposición de una separación forzada como medida cautelar, pena, medida de seguridad o regla de conducta refuerza la idea de que la mujer maltratada es incapaz de tomar una decisión racional, y crea el peligro de que de alguna forma acabe siendo sancionada por reanudar su relación sentimental con el agresor, lo que puede producir un efecto de alienación que aleje a la mujer del sistema penal, haciéndola menos proclive a acudir a él para resolver su situación. ${ }^{96}$ En el

92 Destacan que las " $n$ drop policies" no se basan en un tratamiento igualitario, sino especial, en consideración a las peculiaridades de la relación de pareja, Friedman, L. N./ Shulman, M., "Domestic Violence", cit., p. 98.

93 Vid. Gavison, R., "Feminism and the Public/ Private Distinction", Stanford Law Review, Vol. 45, Issue 1, 1992, pp. 37-38, quien apunta que la intimidad debe proteger la asociación consensual, siempre que el consentimiento y la libertad no sean ilusorios; Karst, K. L., "The freedom of intimate association", Yale Law Journal, Vol. 89, 1980, pp. 629 ss., quien argumenta que esa libertad es un componente necesario del derecho a la intimidad. Vid. un duro alegato contra la posición que justifica la no intervención con base en el derecho de la víctima a su privacidad y autonomía en Choudhry, S./ Herring, J., "Righting domestic violence", cit., pp. 100 ss., quienes apuntan como principal argumento lo difícil que resulta afirmar que la mujer maltratada es capaz de decidir en forma autónoma, afirmación que comparto plenamente. A partir de ahí destacan cómo forzar a la víctima a una separación no deseada puede a largo plazo proteger su autonomía, al liberarla de la influencia del maltratador, y la necesidad de tener en cuenta tanto el interés estatal en acabar con la violencia de género como el posible peligro que supone la vida en común para la integridad de los hijos de la pareja, todo lo cual les lleva a concluir la necesidad de las políticas de protección forzada desde la perspectiva de que el derecho a la intimidad y a la autonomía privada de la mujer no sólo no impide la intervención estatal sino que la exige (pp. 109-111).

${ }^{94}$ Cfr. Larrauri Pijoán, E., “¿Por qué retiran las mujeres maltratadas las denuncias?”, cit., pp. 302303.

95 Parece que tanto la detención como el procesamiento del agresor tienen cierto efecto inhibidor de futuros actos de violencia, en este último caso especialmente cuando la pena impuesta es privativa de libertad. Cfr. Hanna, C., "No right to choose", cit., pp. 1887-1888, con citas.

${ }_{96}$ Cfr. Medina, J. J., Violencia contra la mujer en la pareja, cit., p. 533, quien apunta que la víctima quiere tener la posibilidad de elegir y desea ser tratada como un individuo autónomo en su intento de resolver sus problemas. También Mills, L. G., "Killing her softly: Intimate abuse and the violence of state intervention", Harvard Law Review, Vol. 113, December 1999, núm. 2, p. 556, destaca el efecto de alienación. Sobre la contribución de las estructuras legales que reconocen y 
Faraldo - Suspensión y sustitución de las penas privativas de libertad...

momento de decidir la imposición de medidas cautelares, penas, medidas de seguridad o reglas de conducta que pueden incidir sobre la vida íntima de la mujer hay que introducir mecanismos más flexibles, de forma que sea posible valorar cada caso de forma individual, como resulta obligado cuando se está hablando de la imposición de sanciones de naturaleza penal.

Por ello parece, en principio, más acertado optar por otras medidas, como el tratamiento del maltratador. Al respecto señala LAURENZO que "este tipo de iniciativas repercute en beneficio de la propia víctima, ya que el aprendizaje en el control de la agresividad puede reducir -al menos en alguna medida- el altísimo riesgo de reincidencia implícito en esta clase de delincuentes. Pero, además, cabe recordar que el derecho penal ha de cumplir una función resocializadora que no puede quedar vedada a determinado tipo de autores sólo porque se considere particularmente reprochable la naturaleza del delito cometido". ${ }^{97}$ A mi juicio, en efecto, el tratamiento del maltratador sólo tiene sentido si supone un aumento de la seguridad de la víctima actual o un menor riesgo de victimización de las futuras parejas del maltratador, lo que sólo tendrá lugar si realmente favorece la rehabilitación y reinserción social del penado. Pero no puedo estar de acuerdo con la segunda perspectiva: nadie ha planteado negar a los maltratadores el acceso al tratamiento. Lo que se ha hecho, y eso sí que resulta inusual, es imponer coactivamente el tratamiento en las alternativas a la pena privativa de libertad, aunque no en la ejecución de la pena de prisión, para todos los condenados por delitos relacionados con la violencia de género, precisamente en un momento histórico en que se ha extendido el desencanto en torno a las posibilidades de una intervención resocializadora sobre el delincuente, desencanto que es fruto tanto del abandono de la ideología que en su día la inspiró cuanto de los cambios que está experimentando el Estado social en la actualidad. ${ }^{98}$ Esa imposición obligatoria "no se compadece bien con el respeto a la dignidad y el derecho al libre desarrollo de la personalidad reconocidos a toda persona en el art. 10 de la Constitución",", precisamente los derechos que han llevado a que el tratamiento se configure como una actividad voluntaria en el ámbito penitenciario.

Se corre un gran riesgo si tales programas se implementan con estrategias inadecuadas ${ }^{100}$, por lo que es conveniente tener presentes los estudios sobre los

apoyan la capacidad de autodeterminación de la mujer a su seguridad y a su resistencia ante la violencia masculina vid. Lewis, R., "Making Justice Work", cit., p. 220.

${ }^{97}$ Laurenzo Copello, P., "El modelo de protección reforzada", cit., p. 100; de la misma autora, "La violencia de género en la Ley Integral", cit., p. 24.

${ }^{98}$ Sobre estos cambios vid. por todos Brandariz García, J. A., "Itinerarios de evolución del sistema penal como mecanismo de control social en las sociedades contemporáneas", en Faraldo Cabana, P. (Dir.), Nuevos retos del derecho penal en la era de la globalización, Tirant lo Blanch, Valencia, 2004, pp. 15 ss.

${ }^{99}$ Roig Torres, M., "La suspensión y la sustitución”, cit., p. 130.

100 Vid. por ejemplo Bonino, L., "Los programas de reeducación, reinserción o rehabilitación para varones que ejercen violencia contra las mujeres", ponencia presentada en la Asamblea de Madrid en abril de 2005 ante la Comisión que preparaba la ley regional contra la violencia de género. 
perfiles de los agresores, las causas del maltrato y las posibilidades del tratamiento que ofrece el derecho comparado antes de empezar a utilizarlos con carácter general. Una vez que se determine qué agresores deben ser sometidos a qué tratamiento, creo que la perspectiva de género adoptada en la LO 1/2004 debe tener su reflejo en los programas que se implementen. ${ }^{101}$

Con carácter previo ha de tenerse presente la necesidad de formar en dicha perspectiva a quienes han de llevar a cabo dichos programas: desde el personal de instituciones penitenciarias hasta los voluntarios que colaboran con asociaciones privadas y organizaciones sin ánimo de lucro.

Ya en cuanto al trabajo en beneficio de la comunidad como pena sustitutiva de la de prisión, su efecto resocializador dependerá en buena medida de que se consiga dotar de contenidos adecuados y de su aceptación por los grupos de apoyo a las víctimas de la violencia de género.

Por último, no hay que olvidar que pese a todos los tratamientos que se puedan aplicar y todas las medidas de protección a la víctima que se tomen siempre habrá un número más o menos elevado de agresores reacios a todo cambio de conducta. Frente a ellos sólo es posible tratar de detectarlos cuanto antes ${ }^{102} \mathrm{y}$ desarrollar formas de intervención que maximicen la seguridad de la mujer, mecanismos que, conviene advertir, no necesariamente han de basarse en la prisión y en el alejamiento impuesto.

\footnotetext{
101 Vid. las bases del modelo basado en esta perspectiva en Bowen, E./ Brown, L./ Gilchrist, E., "Evaluating Probation Based Offender Programmes", cit., pp. 225 ss.

102 Parece que la opinión de la mujer acerca de las posibilidades de rehabilitación de su pareja o ex pareja acierta en un número importante de casos. Cfr. Gondolf, E., Batterer Intervention Systems, Thousand Oaks, Sage, 2002, pp. 175-176. Vid. una panorámica de los instrumentos que se emplean para predecir el riesgo de reincidencia en Dutton, D./ Kropp, P., "A review of domestic violence risk instruments", Trauma, Violence and Abuse, Vol. 1, núm. 4, 2000, pp. 171 ss.; Roehl, J./ Guertin, K., "Intimate partner violence: The current use of risk assessments in sentencing offenders", Justice System Journal 21, 2000, pp. 171 ss. Sobre su limitado poder predictivo vid. Gondolf, E. W., "Evaluating batterer counseling programs", cit., p. 620.
} 
Faraldo - Suspensión y sustitución de las penas privativas de libertad...

\section{BIBLIOGRAFÍA}

* ACALE SÁNCHEZ, M., La discriminación hacia la mujer por razón de género en el Código Penal, Reus, Madrid, 2006.

"El artículo primero de la Ley Orgánica 1/2004, de 28 de diciembre, de protección integral contra la violencia de género: el concepto de violencia de género", en FARALDO CABANA, P. (Dir.), Politica criminal y reformas penales, Tirant lo Blanch, Valencia, 2007.

* ALDARONDO, E., "Evaluating the efficacy of interventions with men who batter", en ALDARONDO, E./ MEDEROS, F. (Eds.), Men who batter: Intervention and prevention strategies in a diverse society, New York, Civic Research Institute, 2002.

* ASÚA BATARRITA, A., "El trabajo al servicio de la comunidad como alternativa a otras penas", Estudios de Deusto, 1984.

"Los nuevos delitos de 'violencia doméstica' tras la reforma de la LO 11/2003, de 29 de septiembre", en DÍEZ RIPOLLÉS, J. L. y otros (Eds.), Las recientes reformas penales. Algunas cuestiones, Universidad de Deusto, Bilbao, 2004.

* BENÍTEZ JIMÉNEZ, M. J., "Violencia intrafamiliar: la mujer maltratada”, en RECHEA ALBEROLA, C. (Dir.), La criminología aplicada II, Cuadernos de Derecho Judicial VII1998, CGPJ, Madrid, 1999.

* Berdugo gómez de la torre, J. R., "Alternativas a las penas de prisión. La libertad condicional. El tercer grado penitenciario y los problemas que plantea el art. 36 del Código Penal", en CASTELLANO RAUSELL, P. (Dir.), Las últimas reformas penales, Cuadernos de Derecho Judicial III-2005, Madrid.

* BLAY GIL, E., "El trabajo en beneficio de la comunidad como pena para la violencia familiar", Revista de Derecho Penaly Criminología, núm. 19, 2007.

* BODELÓN GONZÁLEZ, E., "Género y sistema penal: los derechos de las mujeres en el sistema penal”, en BERGALLI, R. (Coord.), Sistema penal y problemas sociales, Tirant lo Blanch, Valencia, 2003.

* BONINO, L., "Los programas de reeducación, reinserción o rehabilitación para varones que ejercen violencia contra las mujeres", ponencia presentada en la Asamblea de Madrid en abril de 2005 ante la Comisión que preparaba la ley regional contra la violencia de género.

* BONTA, J./ WALACE-CAPRETTA, S./ ROONEY, J., "Can Electronic Monitoring make a Difference? An Evaluation of Three Canadian Programs", Crime \& Delinquency, Vol. 46, núm. 1, 2000.

* BOWEN, E./ BROWN, L./ GILCHRIST, E., "Evaluating Probation Based Offender Programmes for Domestic Violence Perpetrators: A Pro-Feminist Approach", The Howard Journal, Vol. 41, núm. 3, July 2002.

* BRANDARIZ GARCÍA, J. A., El trabajo en beneficio de la comunidad como sanción penal, Tirant lo Blanch, Valencia, 2002.

"La sanción de trabajos en beneficio de la comunidad como respuesta a la violencia de género", en PUENTE ABA, L. M. (Dir.), La respuesta penal a la violencia de género. Lecciones de diez años de experiencia de una politica criminal punitivista, Comares, Granada, 2010.

"Itinerarios de evolución del sistema penal como mecanismo de control social en las sociedades contemporáneas", en FARALDO CABANA, P. (Dir.), Nuevos retos del Derecho Penal en la era de la globalización, Tirant lo Blanch, Valencia, 2004.

* BUENO ARÚS, F., "Community Service and Spanish Law”, en AA.VV., Community Service as an Alternative to the Prison Sentence, International Penal and Penitentiary Foundation, Bonn, 1987.

* CANO VAlero, J., “Aspectos psiquiátricos de la violencia doméstica contra la mujer”, en LÓPEZ ARMINIO, M. J. (Coord.), Tratamiento penal de la violencia doméstica contra la mujer, Universidad de Cádiz-Ayuntamiento de Jerez, Jerez, 1999. 
REJ - Revista de Estudios de la Justicia - No 13 - Año 2010

* CARdenal montraveta, S., "Alternativas a la pena de prisión. Especial consideración de la suspensión de la ejecución y la sustitución”, en MIR PUIG, S./ CORCOY BIDASOLO, M. (Dirs.), Nuevas tendencias en política criminal. Una auditoría al Código Penal español de 1995, Julio César Faira - Editor, Montevideo-Buenos Aires, 2006.

* CARreras, M., Aproximación a la jurisprudencia feminista, Ayuntamiento de Alcalá de Henares, Alcalá de Henares, 1994.

* CERES MONTES, J. F., "Las reformas penales en la fase de ejecución de sentencias penales: en especial la suspensión, la sustitución y la expulsión del territorio nacional", en CASTELLANO RAUSELL, P. (Dir.), Las últimas reformas penales, Cuadernos de Derecho Judicial III-2005, CGPJ, Madrid.

* comas D'ARGERmir i CENDRA, M./ QUERALT JIMÉNEZ, J. J., "La violencia de género: política criminal y ley penal", en JORGE BARREIRO, A., y otros, Homenaje al profesor Dr. Gonzalo Rodriguez. Mourullo, Thomson-Civitas, Navarra, 2005.

* CONSEjO GENERAL DEL PODER JUDICIAL, Informes del Consejo General del Poder Judicial sobre las Reformas Penales, CGPJ, Madrid, 2003.

* CORSILlES, A., "No drop policies in the prosecution of domestic violence cases: Guarantee to action or dangerous solution?", Fordham Law Review, Vol. 63, 1994.

* CORVO, K./ JOHNSON, P. J., "Vilification of the "batterer": How blame shapes domestic violence policy and interventions", Aggression and Violent Behavior, 8, 2003.

* Cuello contreras, J./ CARDENAL MURILlO, A., "Bien jurídico y técnica legal de la protección penal de la mujer y otras víctimas de la violencia doméstica", en CARBONELL MATEU, J. C., y otros (Coords.), Estudios penales en homenaje al profesor Cobo del Rosal, Dykinson, Madrid, 2005.

* CUESTA ARZAMENDi, J. L. de la, "La sanción de trabajo en provecho de la comunidad", La Ley 1985-2.

* Cunningham, A./ JAFFe, P. G./ BAKER, L./ DiCK, T./ MALLA, S./ MAZAHERI, N./ POISSON, S., Theory-Derived Explanations of Male Violence Against Female Partners: Literature Update and Related Implications for Treatment and Evaluation, London Family Court Clinic, London, 1998.

* ChOUdhry, S./ HERRING, J., "Righting domestic violence", International Journal of Law, Policy and the Family, Vol. 20, núm. 1, 2006.

* DAVIS, R. C./ TAYLOR, B. G., "Does batterer treatment reduce violence? A synthesis of the literature", Women and Domestic Violence: An Interdisciplinary Approach, 10.

* DOBASH, E. R./ DOBASH, P. R., Women, Violence and Social Change, Routledge, London, 1992.

"Efectividad de los programas penales de tratamiento de maltratadores", en CID MOLINÉ, J./ LARRAURI PIJOÁN, E. (Coords.), La delincuencia violenta. ¿Prevenir, castigar o rebabilitar?, Tirant lo Blanch, Valencia, 2005.

* DUfF, R. A., Punishment, Communication and Community, Oxford University Press, New York, 2000.

* DUTTON, D./ KROPP, P., "A review of domestic violence risk instruments", Trauma, Violence and Abuse, Vol. 1, núm. 4, 2000.

* EADIE, T./ KNIGHT, C., "Domestic Violence Programmes: Reflections on the Shift from Independent to Statutory Provision”, The Howard Journal, Vol. 41, núm. 2, May 2002.

* ECheburúa odriozola, E./ AMOr ANDrÉS, P. J./ CORRAL GARGallo, P. de, "Hombres violentos contra la pareja: trastornos mentales y perfiles tipológicos", Pensamiento Psicológico, núm. 13, 2009.

* ECHEBURÚA, E./ AMOR, P. J., "Hombres violentos en el hogar: perfil psicopatológico y programas de intervención", en RECHEA ALBEROLA, C. (Dir.), La criminología aplicada II, Cuadernos de Derecho Judicial VII-1998, CGPJ, Madrid, 1999. 
Faraldo - Suspensión y sustitución de las penas privativas de libertad...

* echeburúa, E./ Fernández-Montalvo, J., "Hombres maltratadores", en ECHEBURÚA ODRIOZOLA, E./ CORRAL, P. de, Manual de violencia familiar, Siglo XXI, Madrid, 1999.

* ECHEBURÚA, E., y otros, Personalidades violentas, Pirámide, Madrid, 1998.

"Variables predictoras del rechazo, abandono y fracaso terapéutico en hombres violentos contra su pareja tratados psicológicamente en un marco comunitario", International Journal of Clinic and Health Psicology, Vol. 10, núm. 3, 2010.

* EDWARDS, S., "Violence against women: feminism and the law", en GELSTHORPE, L./ MORRIS, A. (Ed.), Feminist perspectives in criminology, Open University Press, Philadelphia, 1990.

* FARALDO CABANA, P., "Razones para la introducción de la perspectiva de género en Derecho Penal a través de la Ley Orgánica 1/2004, de 28 de diciembre, sobre medidas de protección integral frente a la violencia de género", Revista Penal, núm. 17, enero 2006.

"Tendencias de política criminal en el control penal de la violencia de género: alternativas a la privación de libertad y vicisitudes de la ejecución de la pena de prisión para condenados por violencia de género", en FARALDO CABANA, P. (Dir.), Política criminal y reformas penales, Tirant lo Blanch, Valencia, 2007.

"Seguridad de las víctimas de violencia de género. Análisis de las alternativas a la ejecución de las penas privativas de libertad para condenados por delitos relacionados con la violencia de género", en DORES, A. P. (Coord.), Ciências da Emêrgencia. Exercícios interdisciplinares em Ciências Sociais e Humanas, Editora Digital LibrosEnRed, Portugal, 2008.

"Las penas principales de los delitos relacionados con la violencia de género", en AA.VV., Constitución, derechos fundamentales y sistema penal (Semblanzas y estudios con motivo del setenta aniversario del profesor Tomás Salvador Vives Antón). Tomo I, Tirant lo Blanch, Valencia, 2009.

Las probibiciones de aproximación, comunicación y residencia en el Derecho Penal español, Tirant lo Blanch, Valencia, 2009.

"Las penas de los delitos relacionados con la violencia de género. Especial referencia a la prohibición de aproximación y su quebrantamiento", en PUENTE ABA, L. M. (Dir.), La respuesta penal a la violencia de género. Lecciones de diez años de experiencia de una politica criminal punitivista, Comares, Granada, 2010.

* FAulKner, K. K./ COGAN, R./ NOLDER, M./ SHOOTER, G., "Characteristics of men and women completing cognitive/ behavioral spouse abuse treatment", Journal of Family Violence, Vol. 6, núm. 3, 1991

* FERNÁnDEZ, R., "El Derecho Penal como instrumento imprescindible para la prevención de la violencia contra las mujeres", en CALVO GARCÍA, M. (Coord.), La respuesta desde las instituciones y el Derecho frente al problema de la violencia doméstica en Aragón, Dykinson, Madrid, 2005.

* FISCALÍA GENERAL DEL ESTADO, Informe de la Fiscalía General del Estado sobre el tratamiento jurisdiccional de los malos tratos familiares en el añ 1999, Madrid, Instituto de la Mujer, 2000.

* Friedman, L. N./ SHUlman, M., "Domestic Violence. The Criminal Justice Response", en LURIGIO, A. J., y otros (Eds.), Victims of Crime. Problems, Policies, and Programs, Sage, Newbury Park, 1990.

* GARCÍA VITORIA, A., "Tratamiento jurisprudencial actual de la violencia en el ámbito doméstico y familiar”, en MORILLAS CUEVA, L. (Coord.), Estudios penales sobre violencia doméstica, Edersa, Madrid, 2002.

* GAVISON, R., "Feminism and the Public/ Private Distinction", Stanford Law Review, Vol. 45, Issue 1, 1992.

* GÓmez PARDos, L./ LÓPEZ VALENCIA, E. M., "El fenómeno de la violencia doméstica y su tratamiento legislativo e institucional. Especial referencia a la Comunidad 
REJ - Revista de Estudios de la Justicia - No 13 - Año 2010

Autónoma aragonesa", en CALVO GARCÍA, M. (Coord.), La respuesta desde las instituciones y el Derecho frente al problema de la violencia doméstica en Aragón, Dykinson, Madrid, 2005.

* GÓMEZ, S., "Las penas y el tratamiento de los maltratadores", La Ley Penal, núm. 34, 2007.

* GONDOLF, E. W., "Evaluating batterer counseling programs: A difficult task showing some effects and implications", Agression and Violent Behavior, Vol. 9, Issue 6, 2004.

Batterer Intervention Systems, Thousand Oaks, Sage, 2002.

"Limitations of experimental evaluation of batterer programs", Trauma, Violence and Abuse, 2(1), 2001.

* GONDOLF, E. W./ WHITE, R., "Batterer program participants who repeatedly reassault: Psychopathic tendencies and other disorders", Journal of Interpersonal Violence, 16, 2001.

"Batterer Programs: What We Know and Need to Know", Journal of Interpersonal Violence, Vol. 12, núm. 1, 1997.

* GRACIA MARTín, L. (Coord.), Las consecuencias jurídicas del delito en el nuevo Código Penal español, Tirant lo Blanch, Valencia, 1996.

* GRUPO DE ESTUDIOS DE POLÍTICA CRIMINAL, Una propuesta alternativa al sistema de penas y su ejecución, y a las medidas cautelares personales, Málaga, 2005.

* HAIMOVICH, P., "El concepto de malos tratos. Ideología y representaciones sociales", en MAQUIEIRA, V./ SÁNCHEZ, C. (compiladores), Violencia y Sociedad Patriarcal, Fundación Pablo Iglesias, Madrid, 1990.

* HAmbERGER, L. K./ HASTINGS, J. E., "Characteristics of spouse abusers: Predictors of treatment acceptance", Journal of Interpersonal Violence, núm. 1, 1986.

"Counseling male spouse abusers: Characteristics of treatment completers and dropouts", Violence and Victims, núm. 4, 1989

* HAMBY, S., "Partner Violence: Prevention and Intervention", en JASINSKI, J./ WILliaMS, L. (Eds.), Partner Violence: A Comprehensive Review of 20 Years of Research, Newbury Park, Sage, 1998.

* HANNA, C., "No right to choose: mandated victim participation in domestic violence prosecutions", Harvard Law Review, Vol. 109, núm. 8, June 1996.

* HAVA GARCÍA, E., "Suspensión de la ejecución de las penas privativas de libertad (art. 83)", en ÁLVAREZ GARCÍA, F. J./ GONZÁLEZ CUSSAC, J. L. (Dirs.), Comentarios a la Reforma Penal de 2010, Tirant lo Blanch, Valencia, 2010.

* HiRschel, D./ HUTCHISON, I. W., "The Voices of Domestic Violence Victims. Predictors of Victim Preference for Arrest and the Relationship Between Preference for Arrest and Revictimization", Crime \& Delinquency, Vol. 49, núm. 2, April 2003.

* HOYle, C., Negotiating Domestic Violence: Police, Criminal Justice and Victims, Clarendon Press, Oxford.

* HOYLE, C./ SANDERS, A., "Police Response to Domestic Violence: From Victim Choice to Victim Empowerment?", British Journal of Criminology, Vol. 40, núm. 1, 2000.

* Informe del grupo de expertos y expertas en violencia de género del Consejo General del Poder Judicial acerca de los problemas técnicos detectados en la aplicación de la Ley Orgánica 1/2004, de medidas de protección integral contra la violencia de género y en la de la normativa procesal, sustantiva u orgánica relacionada, y sugerencias de reforma legislativa que los abordan, de enero de 2011.

* Íñigo CORroza, E., "Aspectos penales de la LOVG, de 28 de diciembre", en MUERZA ESPARZA, J. (Coord.), Comentario a la Ley Orgánica de Protección Integral contra la Violencia de Género. Aspectos juridico-penales, procesales y laborales, Aranzadi, Pamplona, 2005.

* JASINSKI, J. L./ WILLIAMS, L. M., Partner Violence: A Comprehensive Review of 20 Years of Research, Sage, London, 1998.

* JOHNSON, H., "The role of alcohol in male partners' assaults on wives", Journal of Drug Issues, Vol. 30, núm. 4, 2000. 
Faraldo - Suspensión y sustitución de las penas privativas de libertad...

* JOHnSON, C./ REX, S., "Community Service: Rediscovering Reintegration", en WARD, D., y otros (Eds.): Probation. Working for Justice, $2^{\mathrm{a}}$ ed., Oxford University Press, Oxford, 2002.

* KARST, K. L., “The freedom of intimate association”, Yale Law Journal, Vol. 89, 1980.

* LANGHinRICHSEN-ROHLING, J./ HUSS, M. T./ RAMSEY, S., "The Clinical Utility of Batterer Typologies", Journal of Family Violence, Vol. 15, núm. 1, 2000.

* LARRAURI PIJOÁN, E., “¿Por qué retiran las mujeres maltratadas las denuncias?”, Revista de Derecho Penal y Criminología, núm. 12, 2a época, julio 2003.

"Suspensión y sustitución de la pena en el nuevo Código Penal", Estudios Penales y Criminológicos XIX, 1996.

* LAURENZO COPELLO, P., "La violencia de género en la Ley Integral: valoración políticocriminal”, Jueces para la Democracia, núm. 54, noviembre 2005.

"El modelo de protección reforzada de la mujer frente a la violencia de género: valoración político-criminal”, en AA.VV., La ley de medidas de protección integral contra la violencia de género, Cuadernos penales José María Lidón, núm. 2, Universidad de Deusto, Bilbao, 2005.

* LEWIS, R., "Making Justice Work", British Journal of Criminology, Vol. 44, núm. 2, 2004.

* LlorCa orTegA, J., Manual de determinación de la pena, $6^{\mathrm{a}}$ ed., Tirant lo Blanch, Valencia, 2005.

* LÓPEZ LORENZO, V., "La suspensión y la sustitución de la pena tras la LO 15/2003, de 25 de noviembre, de reforma del Código Penal”, La Ley Penal, núm. 9, año I, octubre 2004.

* LORENTE ACOSTA, M., "Síndrome de agresión a la mujer. Síndrome de maltrato a la mujer", en LÓPEZ ARMINIO, M. J. (Coord.), Tratamiento penal de la violencia doméstica contra la mujer, Universidad de Cádiz-Ayuntamiento de Jerez, Jerez, 1999.

* LOSEL, F., "Evaluating the effectiveness of correctional programs: bridging the gap between research and practice", en BERNFIELD, G. A./ FARRINGTON, D. P./ LESCHIED, A. W. (Eds.), Offender Rehabilitation in Practice: Implementing and Evaluating Effective Programs, John Wiley, Chichester, 2001.

* MADINA, J., "Perfil psicosocial y tratamiento del hombre violento con su pareja en el hogar”, en ECHEBURÚA, E. (Ed.) Personalidades violentas, Pirámide, Madrid, 1994.

* MANJÓN-CABEZA OLMEDA, A., "Violencia de género: discriminación positiva, perspectiva de género y Derecho Penal. Algunas cuestiones sobre la competencia de los nuevos juzgados de violencia sobre la mujer", en ARAGONESES MARTÍNEZ, S., y otros, Tutela penal y tutela judicial frente a la violencia de género, Colex, Madrid, 2006.

* MAQUEDA ABREU, M. L., "La violencia de género. Entre el concepto jurídico y la realidad social", Revista Electrónica de Ciencia Penal y Criminología 08-02 (2006).

* MARTÍN, D., "Battered Women: Society's Problem", en ROBERTS CHAPMAN, J./ GATES, M. (Ed.), The victimization of women, Beverly Hills/ London, Sage, 1978.

* MATA Y MARTín, R. M., "Modificaciones jurídico-penales de la LO 1/2004, de medidas de protección integral contra la violencia de género", Revista de Derecho y Proceso Penal, núm. 15, 2006-1.

* MEDINA ARIZA, J., "El tratamiento del maltratador en el contexto comunitario como respuesta penal: Consideraciones político criminales", en AA.VV., La ley de medidas de protección contra la violencia de género, Cuadernos penales José María Lidón, núm. 2, Universidad de Deusto, Bilbao, 2005.

* MEDINA, J. J., Violencia contra la mujer en la pareja: investigación comparada y situación en España, Tirant lo Blanch, Valencia, 2002.

* MERLOS Chicharro, J. A., "Algunas cuestiones de las diligencias de prueba. Las frecuentes retractaciones de la víctima. La protección de la víctima en el proceso", en AA.VV., Estudios sobre violencia familiar y agresiones sexuales. II 2000. Violencia física y psíquica en el ámbito familiar (1 ${ }^{a}$ reunión de Fiscales encargados del Servicio de Violencia Familiar). Violencia 
REJ - Revista de Estudios de la Justicia - No 13 - Año 2010

habitual en el ámbito familiar, Ministerio de Justicia/ Ministerio de Trabajo y Asuntos Sociales, Madrid, 2000.

* MILLS, L. G., "Killing her softly: Intimate abuse and the violence of state intervention", Harvard Law Review, Vol. 113, núm. 2, December 1999.

* MONTAlBÁN HUERTAS, I., Perspectiva de Género: criterio de interpretación internacional y constitucional, CGPJ, Madrid, 2004.

* MUllender, A., Rethinking Domestic Violence. The Social Work and Probation Response, Routledge, London, 1996.

La violencia doméstica, Paidós, Barcelona, 2000.

* NAvarro Villanueva, C., Suspensión y modificación de la condena penal, Bosch, Barcelona, 2002.

* OSBORNE, R., Apuntes sobre violencia de género, Bellaterra, Barcelona, 2009.

* Paloma MONTAÑO, L. M., "Problemas técnicos detectados en la aplicación de la LO $1 / 2004$, de medidas de protección integral contra la violencia de género", en MARCHAL ESCALONA, A. N. (Dir.), Manual de lucha contra la violencia de género, Aranzadi ThomsonReuters, Cizur Menor, 2010.

* PEled, E./ EISIKOVITS, Z. C./ ENOSH, G./ WINSTOK, Z., "Choice and empowerment for battered women who stay: toward a constructivist model", Social Work, Vol. 45, núm. 1, 2000.

* POZUELO PÉREZ, L., "La pena de trabajos beneficio de la comunidad", ICADE septdic. 1997.

* PUENTE SEgURA, L., Suspensión y sustitución de las penas, La Ley, Madrid, 2009.

* RAMON RIBAS, E., "Las relaciones entre los delitos de violencia de género y violencia doméstica”, en PUENTE ABA, L. M. (Dir.), La respuesta penal a la violencia de género. Lecciones de diez años de experiencia de una política criminal punitivista, Comares, Granada, 2010.

"Los delitos de violencia de género: objeto de protección", en RAMON RIBAS, E./ ARROM LOSCOS, R./ NADAL GÓMEZ, I., La protección frente a la violencia de género: tutela penaly procesal, Dykinson, Madrid, 2010.

* REDOndo ILlescas, S./ GARRIDO GENOVÉS, V., "Propuesta para el tratamiento en la comunidad de los agresores interfamiliares. Propuesta desarrollada a petición del Consejo General del Poder Judicial para la discusión de la misma en la Comisión Interinstitucional creada al efecto", 21 de mayo de 1999, disponible en http://www.observatorioviolencia.org/Upload/DOC68_MALTRATADORESFAMILI ARES.pdf.

* RENZEMA, M./ MAYO-WILSON, E., "Can electronic monitoring reduce crime for moderate to high-risk offenders?”, Journal of Experimental Criminology, Vol. 1, núm. 2, 2005.

* ROBLEDO VILLAR, A., "Los elementos personales de la agresión familiar", en AA.VV., Estudios sobre violencia familiar y agresiones sexuales, Tomo I, Madrid, 2000.

* Rodríguez mourullo, G. (Dir.), Comentarios al Código Penal, Civitas, Madrid, 1997.

* ROEHL, J./ GUERTIN, K., "Intimate partner violence: The current use of risk assessments in sentencing offenders", Justice System Journal, 21, 2000.

* ROIG TORRES, M., "La suspensión y la sustitución de las penas privativas de libertad de los delitos relacionados con la violencia de género", Revista de Derecho y Proceso Penal, núm. 15, 2006-1.

* SÁNCHEZ GARCÍA DE PAZ, I., “Artículo 83”, en GÓMEZ TOMILLO, M. (Dir.), Comentarios al Código Penal, Lex Nova, Valladolid, 2010.

* SÁnCheZ YllerA en VIVES ANTÓN, T. S. (Coord.), Comentarios al Código Penal de 1995. Volumen I (Articulos 1 a 233), Tirant lo Blanch, Valencia, 1996.

* SANZ MUlas, N./ GONZÁlez BUSTOS, M. A./ MARTínEZ GAlLEGO, E. M. (Coords.), Ley de Medidas de Protección Integral contra la Violencia de Género (LO 1/2004, de 28 de diciembre), Iustel, Madrid, 2005. 
Faraldo - Suspensión y sustitución de las penas privativas de libertad...

Alternativas a la pena privativa de libertad, Colex, Madrid, 2000.

* SHAMAI, M., "Couple therapy with battered women and abusive men: does it have a future?”, en EDLESON, J. L./ EISIKOVITS, Z. C. (Eds.), Future interventions with battered women and their families, Sage, Thousand Oaks, 1996.

* SCHNEIDER, E. M., "The Violence of Privacy", Connecticut Law Review, Vol. 23, 1991.

* SCOURfield, J. B./ DOBASH, R. P., "Programmes for Violent Men: Recent Developments in the UK", The Howard Journal, Vol. 38, núm. 2, May 1999.

* ShERMAN, L. W./ BERK, B. A., "The specific deterrent effects of arrest for domestic assault", American Sociological Review, Vol. 49, 1984.

* SuÁREZ-MiRA RODRÍGUEZ, C., La imputabilidad del consumidor de drogas, Tirant lo Blanch, Valencia, 2000.

* TAmarit Sumalla, J. M., "La sustitución de las penas de prisión”, en Álvarez GARCÍA, F. J./ GONZÁLEZ CUSSAC, J. L. (Dirs.), Comentarios a la Reforma Penal de 2010, Tirant lo Blanch, Valencia, 2010.

* TÉllez Aguilera, A., "La reforma del Código Penal y sus implicaciones penológicas”, La Ley Penal, núm. 1, año I, enero 2004.

Nuevas penas y medidas alternativas a la prisión, Edisofer, Madrid, 2005.

* TORRES ROSELL, N., "Las sanciones penales en la lucha contra la violencia de género", en VILLACAMPA ESTIARTE, C. (Coord.), Violencia de género y sistema de justicia penal, Tirant lo Blanch, Valencia, 2008.

* Ventura, L. A./ DAVIS, G., "Domestic Violence: Court Case Conviction and Recidivism", Violence Against Women, Vol. 11, núm. 2, 2005.

* WAlKER, L. E., "Treatment Alternatives for Battered Women", en ROBERTS CHAPMAN, J./ GATES, M. (Ed.), The victimization of women, Beverly Hills/London, Sage, 1978.

The Battered Woman Syndrom, Springer, New York, 1984.

* WALTERS, G., "Disposed to aggress? In search of the violence-prone personality", Aggression and Violent Behavior, Vol. 5, Issue 2, 2000.

* WILliams, K. R., "Arrest and intimate partner violence: Toward a more complete application of deterrence theory", Aggression and Violent Behavior, 10, 2005.

* WILLS, D., "Domestic violence: The case for aggressive prosecution", UCLA Women's Law Journal, Vol. 7, núm. 2, 1997.

* Wooldredge, J./ THistlethwaite, A., "Court Dispositions and Rearrest for Intimate Assault”, Crime \& Delinquency, Vol. 51, núm. 1, 2005.

* Zoellner, L./ FeEny, N./ ÁlvareZ, J./ WATlington, C./ O’NEILL, M./ ZAGER, R./ FOA, E., "Factors associated with the completion of the restraining order process in female victims of partner violence", Journal of Interpersonal Violence, Vol. 15, núm. 10, 2000. 